\title{
User Perspectives on Emerging Mobility Services: Ex Post Analysis of Kutsuplus Pilot
}

\begin{abstract}
Kutsuplus was a novel, flexible micro transit service (FMTS) operating in Helsinki during 2012 to 2015. The service included a range of new technological development, ranging from routing algorithm to marketing and user interface. However, at the end of 2015, the service ceased due to budgetary constraints. In the context of service discontinuation, and the lack of in-depth understanding of user perspectives about urban FMTS, this paper aims to uncover the perspectives of the users of the service, users that discontinued using the service during its operation, and persons who did not use the service. The methodological approach is based on a questionnaire, with mapping capabilities enabling collection of georeferenced data. Questionnaire results are validated using actual Kutsuplus trip analysis. The results show that Kutsuplus users were a diverse group both when considering socio-economic status and travel behavior. In addition, the results include detailed analysis of stated trip characteristics, including spatial analysis of trip origins and destinations. Furthermore, the results include qualitative analysis of respondents' opinions and recommendations about positive and lacking FMTS features. The paper ends with a summary of positive Kutsuplus features, followed by the discussion of aspects for future deployment, including end-user and service area analysis, marketing strategy, and service usability. Finally, the paper provides recommendations for further research on FMTS.
\end{abstract}

Key words: Flexible Micro Transport Service; Automated Demand Responsive Transport; Transportation Network Company; Urban Mobility; Paratransit; 


\section{INTRODUCTION}

Transport plays an essential role in tackling sustainability challenges in the cities of the $21^{\text {st }}$ century (Banister, 2008). A range of opportunities arise from the increasing number of available transport modes, range of pricing options, mobility-on-demand services, Mobility-as-a-Service (MaaS) concepts and changing user expectations (Pangbourne, Stead, Mladenović, \& Milakis, 2018). In relation to these opportunities, flexible micro transport services (FMTS) are located in a continuum between taxi and bus service, ranging from informal transport to area wide networks. These innovative services aim for near or door-to-door mobility, providing an alternative to passenger car use (Sihvola, Jokinen, \& Sulonen, 2012). Consequently, FMTS provide an alternative between the high flexibility and high cost taxi service, and the low price, and medium flexibility bus-based public transport. Due to its flexibility FMTS has the potential to fill many roles in a MaaS scheme by replacing or complementing existing fixed route public transport (Giorgio Ambrosino, Nelson, Boero, \& Pettinelli, 2016; Hensher, 2017). The additional dimension of FMTS flexibility is variability of service and fare level. An example of recent relevant development includes the emergence of transportation network companies, such as Uber, Lyft, and Split, that are centered on user-focused demand-responsiveness and sharing (Anderson, 2014; Cannon \& Summers, 2014; Koffmann, 2016).

FMTS builds on the established principles of previous concept of demand-responsive transport (DRT). Operating without fixed routes DRT has commonly been associated with rural areas having a lack of public transport, or as service for people with disabilities (Mageean \& Nelson, 2003; Velaga, Nelson, Wright, \& Farrington, 2012). However, with the advent of informationcommunication (Black \& Van Geenhuizen, 2006) and real-time routing technology (Agatz, Erera, Savelsbergh, \& Wang, 2012; Diana, 2006), DRT services have the potential to become a viable transport option in the urban areas (Jokinen, Sihvola, Hyytia, \& Sulonen, 2011). This research focuses on Kutsuplus, the large-scale FMTS pilot in the Helsinki Capital Region (HCR), Finland (Jokinen, 2016; Jokinen, Sihvola, \& Mladenovic, 2017; Rissanen, 2014). The service has been operational from October 2012 until the end of 2015, under the responsibility of the regional transport authority, Helsinki Region Transport (HSL). The HSL Executive Board decided that Kutsuplus in its current form would cease at the end of 2015, due to financial reasons (Jokinen et al., 2017). Despite the cancelation, as a unique pilot in an urban area, 
Kutsuplus provides valuable lessons for planning and policy-making of future urban FMTS. In particular, the pilot is important for providing lessons on user perspectives and transferability, which is the focus of this paper. To this end, the next section presents a more detailed description of the Kutsuplus pilot. Section three presents the methodological approach based on a questionnaire. Section four includes results, while section five provides a discussion on lessons

learned from the pilot, with conclusive points and suggestions for future research topics. This research builds upon the understanding of operational characteristics and technological advancement, as well as experiences from previous DRT case studies (Brake, Mulley, Nelson, \& Wright, 2007; Brake, Nelson, \& Wright, 2004; Mageean \& Nelson, 2003; Mulley \& Nelson, 2016; Nelson, Wright, Masson, Ambrosino, \& Naniopoulos, 2010).

\section{BACKGROUND}

\subsection{Service Overview}

In order to contextualize the development trajectory of Kutsuplus (Kalliomaki, Eloranta, \& Sassoli, 2004), this section presents the essential background information about the service. The Kutsuplus service was an advanced form of FMTS operated by HSL. However, Finland had previous experience with DRT (G Ambrosino et al., 2000) with recommendations for a national policy as early as 2003 (Ambrosino et al., 2004; Nelson et al., 2010). The Kutsuplus service relied on a combination of technologies (Jokinen, Sihvola, \& Mladenovic, 2017), including automated vehicle location, trip combination optimization, vehicle routing, and travel time estimates (Häme, 2011). The user would receive trip offer(s) by requesting a trip via browserbased interface or via SMS. Trip request involved specifying origin and destination on a map, number of seats needed, reserve space for a pram if needed and earliest possible departure time. After this a set of possible journey options were displayed, with corresponding price information. With the SMS option, the origin and destination stop identifiers and a price limit were sent as a message. The return message would contain information about the ordered journey. The earliest possible departure time was initially a maximum of 60 minutes; in later stages this was shortened to 45 minutes during normal operation and 30 minutes on busy campaign days. The offer to the user would then include pickup time, estimated time window for arrival, and predefined price. The trip offering and vehicle routing process was completely automated, without the need to 
involve the driver or the operator. The service used an advance payment with a user account having preloaded monetary value. In addition to the option of an individual account wallet, companies had an option to establish their own company account wallet.

The service started with 10 microbuses in October 2012, with an additional five vehicles being added on November 18, 2013. These microbuses had a seating capacity of nine passengers, with side steps, wireless Internet access, and real-time passenger travel information about the expected time of arrival at the destination. Service was stop-to-stop, without requiring transfer between transport vehicles. At the start of the pilot, the operating time was 9:00 - 17:00, only during weekdays. This time was extended to 7:30 - 18:30, 6:00 - 23:00, and 6:00 - 24:00 in November 2012, November 2013, and November 2014, respectively. Figure 1 below shows the Kutsuplus service area, defined roughly as the inner side of the ring road one, encircling the Helsinki downtown area. The service area was within 9 kilometers radius of the city center roughly delimited by the inner ring road. In the year 2012, the mode split for residents of the City of Helsinki was 34\% public transport, 29\% passenger car, 29\% walking, 6\% bicycling, and 2\% other (Lindeqvist, Kantele, Räty, Elolähde, \& Vihervuori, 2013). In addition, there were about one thousand bus stops in the area. These stops were supplemented with around fifty virtual stops in places where the density of the regular bus stops was too low, or to account for special case situations, such as proximity to hobby areas for kids or an important location for the elderly that reduces the walking distance on a slippery surface during winter. It is important to note that service was subsidized by the member municipalities of the HSL region. 


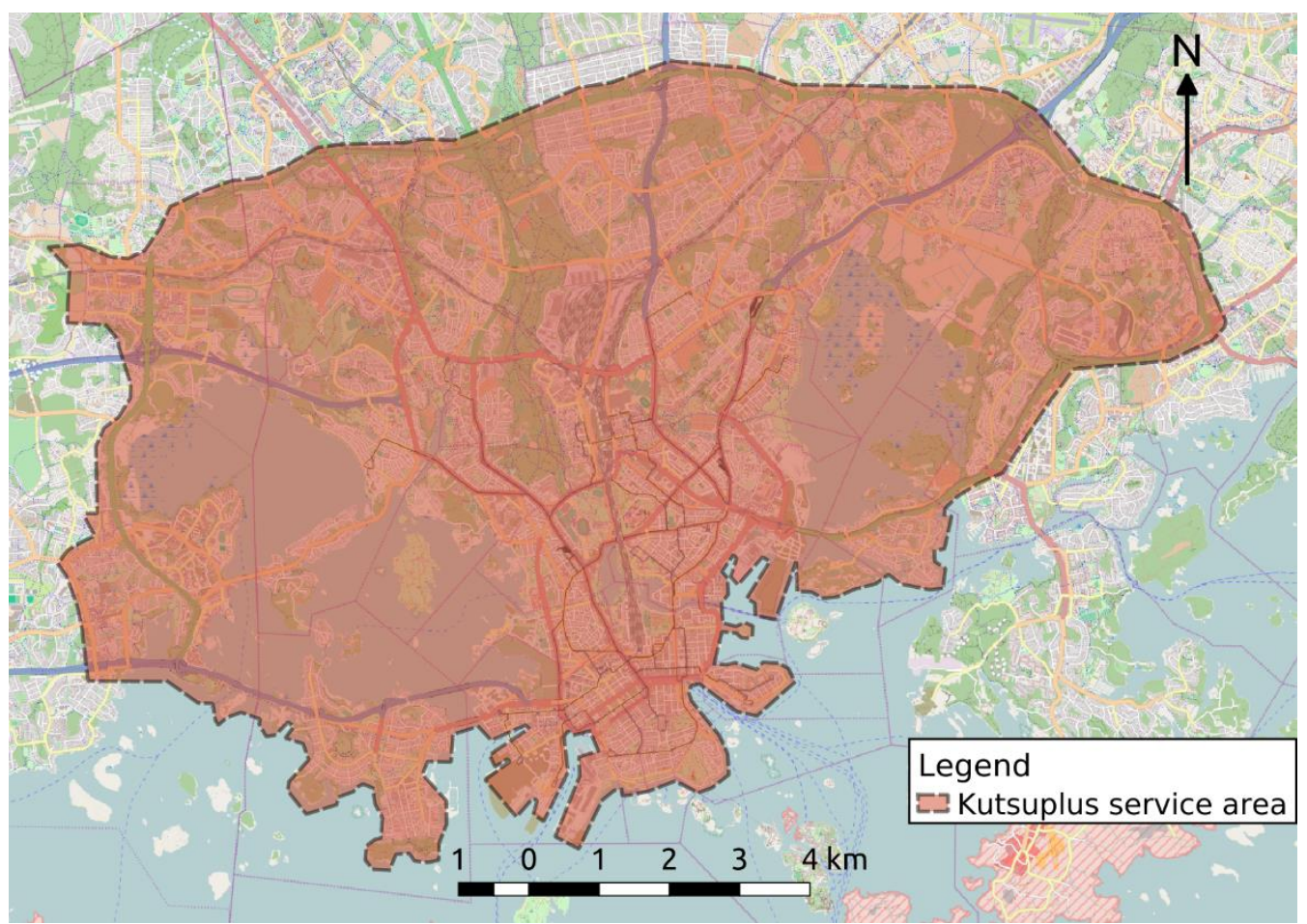

Figure 1: Kutsuplus service area (Background map @ ( Open Street Map)

HSL made several small marketing campaigns about Kutsuplus service, using digital, social and conventional media, such as outdoor and print ads. The annual marketing budget was ranging between $€ 100,000$ and $€ 200,000$, divided evenly during the year. Thus, each campaign was relatively small, amounting to around $5 \%$ of operating costs (Jokinen, Sihvola, \& Mladenovic, 2017). In addition, there was a dilemma in choosing the marketing target group. In general, the marketing emphasis was on service novelty, smart technology, and a futuristic way of traveling. The campaign focused on online platform, asking users about potential Kutsuplus use scenarios. Moreover, social media advertising through posts and testimonials has been used extensively, complemented with printed material about the ordering process. For three campaigns, free trialdays were offered. In addition, celebrities were involved in trying out the service to attract publicity. Decisions about pricing schemes and marketing were not done in coordination.

There were several service classes across the pilot period (Jokinen, Sihvola, \& Mladenovic, 2017). In general, the trip pricing was based on the fixed starting fee (ranging from $€ 1.5$ in 2012 to $4.1 €$ in 2015$)$, and the kilometer price $(€ 0.15$ to $€ 0.53)$ calculated as the direct distance between origin and destination yielding an average fare of around $€ 5.5$ per trip in 2015 . The 
service classes differed in flexibility. The "Economy" option had most flexibility with regards to the passenger travel time, while the "Fast" option offered direct service between stops without trip pooling. The last year of the Kutsuplus pilot service classes were replaced with a $20 \%$ discount between 10AM-2PM. The service has included a group discount of $20 \%$ for 2 passenger bookings, $30 \%$ for 3 passenger bookings, $40 \%$ for 4 passenger bookings and $50 \%$ for bookings with 5 passengers or more. In early 2015, time-of-day based discounts were introduced in the service, introducing lower "happy-hour" pricing for trips outside of the peak period. In comparison, the internal ticket price for public transport is $€ 3$, two-zone ticket is $€ 5$, while for those having a season ticket one average trip approximately costs $€ 0.66$. Users could obtain an estimate of the price for their intended trip using a pricing simulator on the Kutsuplus web page.

\subsection{Operational Experiences}

During the operation, the number of annual service trips grew steadily, reaching almost 100,000 trips in 2015 (Rissanen, 2016). In addition, the vehicular efficiency showed an upward trend, efficiently combining trips, despite the limited fleet capacity. By 2015, vehicles had almost 55,000 annual vehicle hours, and around 1.8 trips per vehicle hour. Similarly, the trend has been positive in the number of registered Kutsuplus accounts, reaching a total of 32,193 users. Moreover, users requested service expansion geographically and temporally on a daily basis. The reliability of the service was high, as $35 \%$ of pick-ups were within a +/-30-second range (Rissanen, 2016). A customer satisfaction survey conducted during the pilot by HSL showed an overall rating of 4.7 out of five, which is higher compared to the typical score of 4.2 for traditional public transport in the HSL region. In total from 2012 to 2015, the service had an operating revenue of $€ 895,400$, and service costs of $€ 7,821,400$. Including personnel expenses of $€ 907,800$, other expenses and depreciation, resulted in net income being -€7,913,200. However, despite the continued increase in subsidies through the operating period, the subsidy per trip decreased steadily. However, the Kutsuplus subsidy of just above €20 per trip in 2015 was much higher than the corresponding average subsidy for all public transport trips in the HSL area of $€ 0.85$ (HSL, 2015). Moreover, the range of potential wider benefits has been identified, including for example reduction in traffic accidents, environmental pollution, parking area construction and land use, road infrastructure maintenance, etc. (HSL, 2016). 


\section{METHODOLOGICAL APPROACH}

In order to investigate user perspectives about Kutsuplus, this research has focused on understanding the socio-economic and travel behavior background of users. In addition, the research focus was on underlying reasons for using or not using the service, as well as on gathering user comments and recommendations. For the research approach, the research team has decided to use a web-based questionnaire with mapping capabilities, commonly used in participatory planning practice (Salonen, Broberg, Kyttä, \& Toivonen, 2014). The survey was available in three languages: English, Finnish and Swedish. To make the user interface easy and attractive for the respondent, the survey was divided into sections. The questionnaire structure is shown in Figure 2. The first part of the survey asked about the respondent's background. In addition, this part involved the main filtering question about the use of the Kutsuplus service. Based on the answer to the filtering question the survey divides the participant in three user groups, i.e., those that have used Kutsuplus and would have continued using it (group 1), those that have used Kutsuplus and have decided to stop (group 2), and finally, those that have never used Kutsuplus (group 3). Based on this filtering question, the respondent was asked different questions about the Kutsuplus service. 


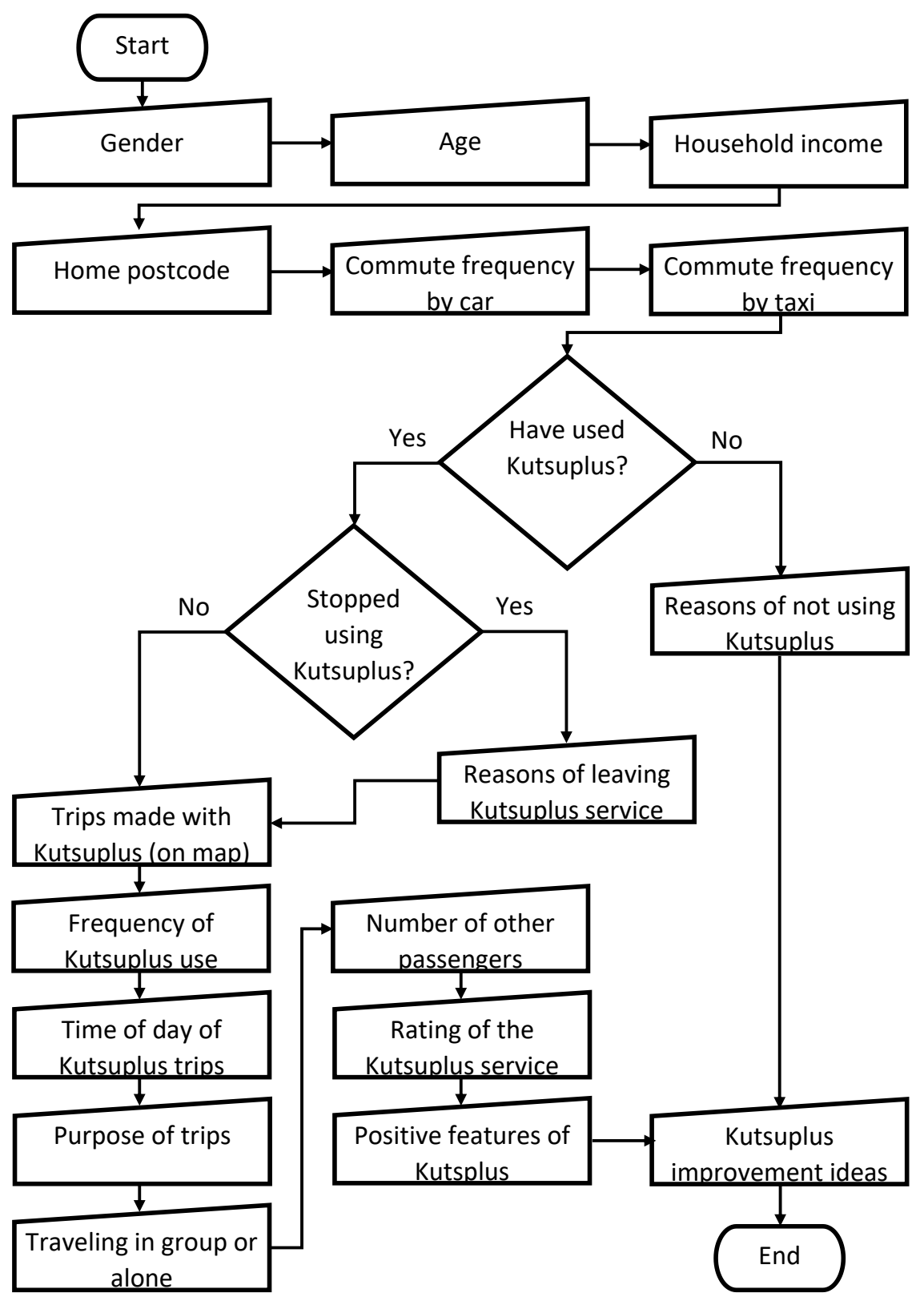

Figure 2: Questionnaire structure

In the second section of the questionnaire, participants from group 1 and 2 were asked to provide georeferenced information about their trip origins and destinations while using Kutsuplus (Figure 3). The third questionnaire section asked for information about the trips made and user experiences with Kutsuplus service, including reasons for using and discontinuing the service. This section was also the only section those that have not used the service would see, as they would be asked about their reasons for not using the service, and for recommendations on 
improving the Kutsuplus service in the future. To complete the survey the respondent was not required to answer every question, only the filtering question was mandatory to complete the questionnaire. The survey was active from April 15 to May 6, 2016. The survey was advertised in three different campaigning rounds with one-week intervals. The link to the survey was advertised on social media such as local Facebook groups, Twitter, and sent by email to registered Kutsuplus users. In total, the link was posted to 24 Facebook groups, with a total of over 62700 members at the time. The groups can be divided into 3 categories, student matters (20600 members), transportation and urban planning (12100 members), and general neighborhood or region groups (30000 members). The exact number of individual members in these groups is likely to be lower as membership in multiple groups is possible. On twitter five different hashtags were used: \#Helsinki, \#Espoo, \#Paakaupunki (Finnish for capital city), \#HSL and, \#Kutsuplus. Due to the nature of social media, the actual number of potential respondents reached is difficult to assess. However, the email was sent to the 32,193 Kutsuplus user accounts.
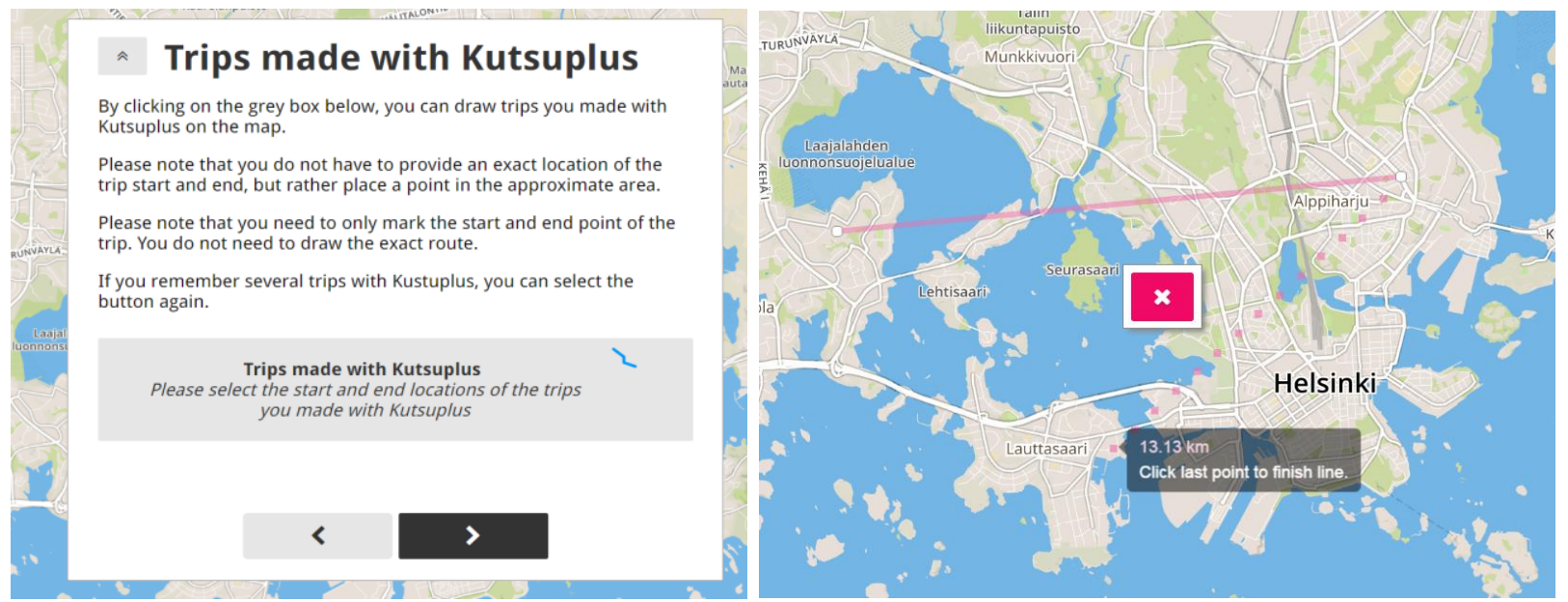

Figure 3: User input of trip origins and destinations with example of data collection

Collected data was checked for incomplete responses, and partially translated. Georeferenced trips have been filtered through visual analysis. This process has included the removal of some very short trips or trips outside of the Kutsuplus service area, as these might have resulted from the respondents' unfamiliarity with the mapping feature in the questionnaire. As a further step, the input data was compared with trip data collected by Kutsuplus. This data, containing the identifiers of the origin and destination stops, was supplemented with stop coordinates to enable spatial analysis. Furthermore, taxi trip length distribution was calculated based on travel survey 
data from 2007, 2008 and 2012 collected by HSL. Based on the data collected, the analysis includes the following groups:

- Quantitative analysis of user responses;

- Geospatial analysis of user-provided trips, validated using trip data collected by Kutsuplus;

- Qualitative analysis of users' comments;

\section{RESULTS}

The total number of survey respondents was 1440 . The total response rate is difficult to assess due to the way the respondents were recruited trough social media channels. However, if respondents that stated that they had used Kutsuplus was indeed registered Kutsuplus users, the survey response rate for Kutsuplus users is around 3 percent, calculated as the fraction stated Kutsuplus users in the survey of all registered Kutsuplus users. The item-response rate varies depending on survey question due to the nature of the mandatory and optional question asked.

\subsection{Summary Results}

Table 1 shows the cumulative number of responses for the background information questions. Table 2 below shows the summary of the responses for questions regarding Kutsuplus service. The respondents of the survey represent a broad spectrum of people from every age and income class. Most of the questionnaire respondents were former Kutsuplus users (72\%). The majority of respondents had used Kutsuplus two to five times. Moreover, the highest percentage of trips had social or recreational purpose, similar to general trends in HSL region. Trips were spread out across the day, with peak in the afternoon. Respondents were usually traveling alone, while there were one to three other passengers sharing the vehicle simultaneously. Finally, Table 2 also shows reasons for choosing Kutsuplus, for stopping using it, and for not using it at all. 
Table 1: Respondents' background information

\begin{tabular}{|c|c|c|c|c|}
\hline Question & Stated Answers & $\begin{array}{c}\text { No. of } \\
\text { Responses }\end{array}$ & $\begin{array}{c}\text { Total } \\
\text { Responses }\end{array}$ & $\begin{array}{c}\text { Item } \\
\text { nonresponse } \\
\text { rate }\end{array}$ \\
\hline Gender & $\begin{array}{c}\text { Male } \\
\text { Female } \\
\text { Other }\end{array}$ & $\begin{array}{c}618 \\
791 \\
8\end{array}$ & 1417 & 0,016 \\
\hline Age groups & $\begin{array}{c}\text { 18-30 years } \\
\text { 31-45 years } \\
\text { 46-65 years } \\
66 \text { and Above } \\
\text { Other }\end{array}$ & $\begin{array}{c}283 \\
561 \\
464 \\
109 \\
8\end{array}$ & 1425 & 0,010 \\
\hline $\begin{array}{l}\text { Household Income } \\
\qquad(€)\end{array}$ & $\begin{array}{c}\text { Less than } 2000 \\
2001-4000 \\
4001-6000 \\
6001-8000 \\
\text { More than } 8000 \\
\text { Other }\end{array}$ & $\begin{array}{l}184 \\
382 \\
302 \\
212 \\
207 \\
113\end{array}$ & 1400 & 0,028 \\
\hline Car usage frequency & $\begin{array}{c}\text { Never } \\
\text { Daily } \\
\text { 2-4 times a Week } \\
\text { Once a Week } \\
\text { Once a Month } \\
\text { Other }\end{array}$ & $\begin{array}{l}319 \\
302 \\
318 \\
182 \\
237 \\
111\end{array}$ & 1358 & 0,057 \\
\hline $\begin{array}{l}\text { Taxi usage } \\
\text { frequency }\end{array}$ & $\begin{array}{c}\text { Never } \\
\text { Daily } \\
\text { 2-4 times a Week } \\
\text { Once a Week } \\
\text { Once a Month } \\
\text { Other }\end{array}$ & $\begin{array}{c}240 \\
4 \\
39 \\
136 \\
634 \\
393\end{array}$ & 1053 & 0,269 \\
\hline Kutsuplus usage & $\begin{array}{c}\text { Used and Continued } \\
\text { Used and Discontinued } \\
\text { Never Used }\end{array}$ & $\begin{array}{c}939 \\
90 \\
390\end{array}$ & 1419 & 0,015 \\
\hline
\end{tabular}


Table 2: Summary of responses related to Kutsuplus service

\begin{tabular}{|c|c|c|c|c|}
\hline Question & Answer Choices & $\begin{array}{c}\text { No. of } \\
\text { Responses }\end{array}$ & $\begin{array}{c}\text { Total } \\
\text { Responses }\end{array}$ & $\begin{array}{c}\text { Item nonresponse } \\
\text { rate (only eligible } \\
\text { respondents } \\
\text { considered) }\end{array}$ \\
\hline Trips by Kutsuplus & $\begin{array}{c}\text { 1 time } \\
\text { 2-5 times } \\
\text { 6-10 times } \\
\text { 11-20 times } \\
\text { 21-30 times } \\
\text { Over } 30 \text { times }\end{array}$ & $\begin{array}{c}77 \\
271 \\
195 \\
167 \\
72 \\
126\end{array}$ & 908 & 0,118 \\
\hline Purpose of trips & $\begin{array}{l}\text { Going to work/school } \\
\text { Business-related trip } \\
\text { Shopping trip } \\
\text { Social/recreational trip }\end{array}$ & $\begin{array}{c}269 \\
263 \\
68 \\
575\end{array}$ & 1175 & 0,147 \\
\hline $\begin{array}{c}\text { Trip time during the } \\
\text { day }\end{array}$ & $\begin{array}{l}\text { Morning (6 to } 10) \\
\text { Mid-day (10 to } 15) \\
\text { Afternoon (15 to } 18) \\
\text { Evening (18 to } 21) \\
\text { Late Night (21 to } 24)\end{array}$ & $\begin{array}{l}248 \\
299 \\
414 \\
359 \\
166\end{array}$ & 1486 & 0,113 \\
\hline $\begin{array}{c}\text { Accompanying } \\
\text { passengers }\end{array}$ & $\begin{array}{c}\text { Alone } \\
\text { 2-3 Group } \\
\text { 4-9 Group }\end{array}$ & $\begin{array}{c}662 \\
140 \\
54\end{array}$ & 856 & 0,168 \\
\hline $\begin{array}{c}\text { Other passengers in } \\
\text { the vehicle }\end{array}$ & $\begin{array}{c}0 \\
1 \\
2-3 \\
3+\end{array}$ & $\begin{array}{c}174 \\
306 \\
298 \\
63\end{array}$ & 841 & 0,183 \\
\hline $\begin{array}{l}\text { Reasons of making } \\
\text { trip by Kutsuplus }\end{array}$ & $\begin{array}{c}\text { Lack of good public transport connection } \\
\text { Low cost of Kutsuplus compared to taxi } \\
\text { Fast travel choice compared to public } \\
\text { transport } \\
\text { Lack of parking spaces and other problems } \\
\text { with using personal car } \\
\text { Easiness of ordering a trip } \\
\text { Other }\end{array}$ & $\begin{array}{c}379 \\
529 \\
516 \\
99 \\
\\
204 \\
132\end{array}$ & 1727 & 0,155 \\
\hline Reasons for & Booking and paying fare was complex & 16 & 57 & 0,367 \\
\hline
\end{tabular}




\begin{tabular}{|c|c|c|c|c|}
\hline $\begin{array}{c}\text { discontinuing } \\
\text { Kutsuplus }\end{array}$ & $\begin{array}{l}\text { Long walking distance to stop/pickup point } \\
\text { Trip cost of Kutsuplus was high } \\
\text { Use other public transport (bus, tram, } \\
\text { metro) } \\
\text { Other }\end{array}$ & $\begin{array}{c}6 \\
10 \\
25 \\
41\end{array}$ & & \\
\hline $\begin{array}{l}\text { Reasons for not } \\
\text { using Kutsuplus }\end{array}$ & $\begin{array}{l}\text { I did not know about this service at all } \\
\text { I had some information about the service } \\
\text { but not enough to order the service } \\
\text { The service had no pickup point near my } \\
\text { home or work place } \\
\text { The service area did not include other } \\
\text { places of my interest } \\
\text { Fare was too high } \\
\text { Other }\end{array}$ & $\begin{array}{l}62 \\
107 \\
56 \\
38 \\
37 \\
87\end{array}$ & 300 & 0,231 \\
\hline
\end{tabular}

\subsection{Respondents' Characteristics}

Figure 4 shows Kutsuplus use in relation to respondents' age and income. The age and wealth distributions within the sample differs between the groups defined by Kutsuplus usage. Overall Kutsuplus was used by all age and income groups. However, the respondents in the sample who did not try Kutsuplus tend to be younger and have lower income. A probable explanation is the demographics of the various data collection channels. It is safe to assume that the respondents reached by e-mail include mostly Kutsuplus registered users, while the persons reached via Twitter and Facebook contain a mix of Kutsuplus users and non-users. In addition, the sample did not indicate large differences among Kutsuplus users with respect to gender. 


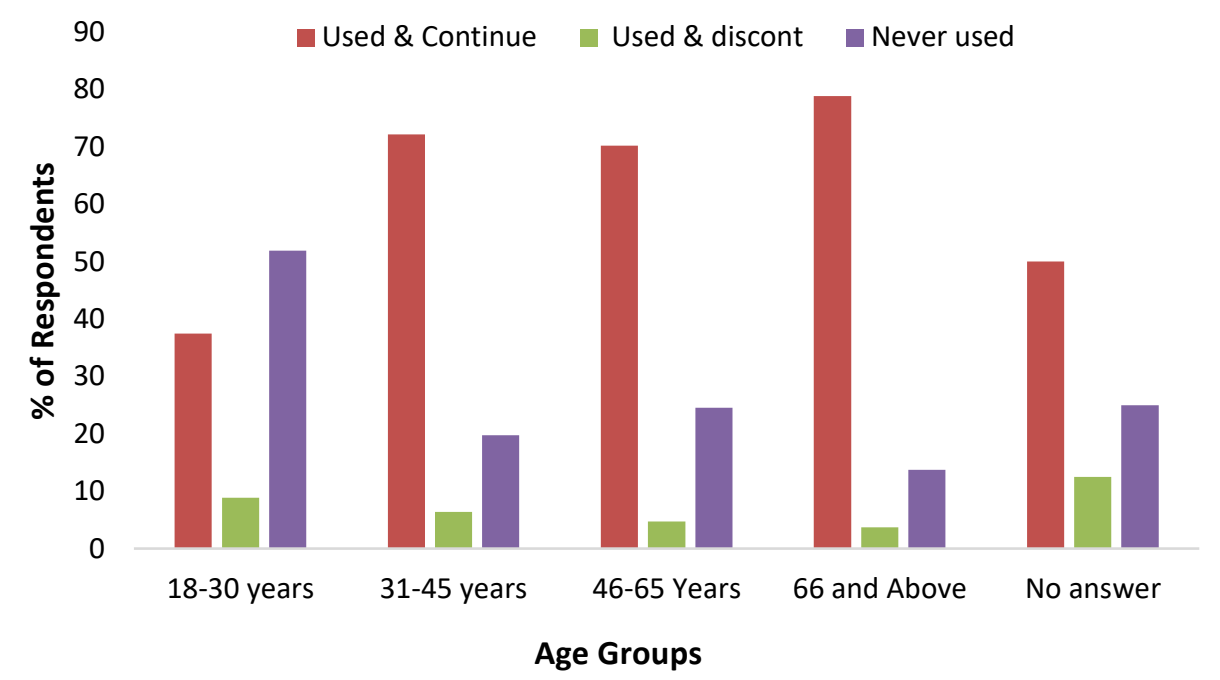

a)

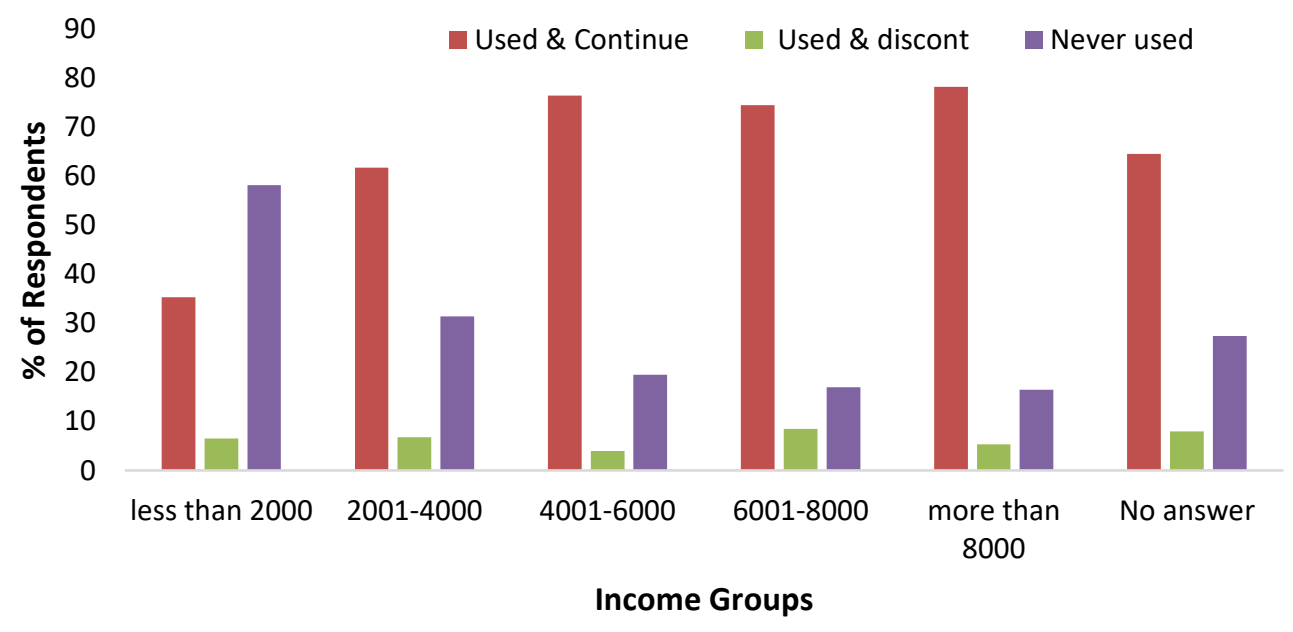

b)

Figure 4: Kutsuplus use in relation to a) Age and b) Income

Figure 5 depicts respondents' Kutsuplus use in relation to car use and taxi usage frequency. In general, Kutsuplus has achieved a solid user base from those that regularly use car (daily and up to four times a week). However, contrary to the expectations, the majority of respondents that have used and planned to continue using Kutsuplus still belonged to less frequent car users. On the contrary, the majority of respondents that have used Kutsuplus rarely use taxi service. One category of respondents that have never used Kutsuplus have also never used car or taxi, which places them in a category mainly dependent on conventional public transport. Most of the respondents of the survey were living within the Kutsuplus service area, as shown in Figure 6. 


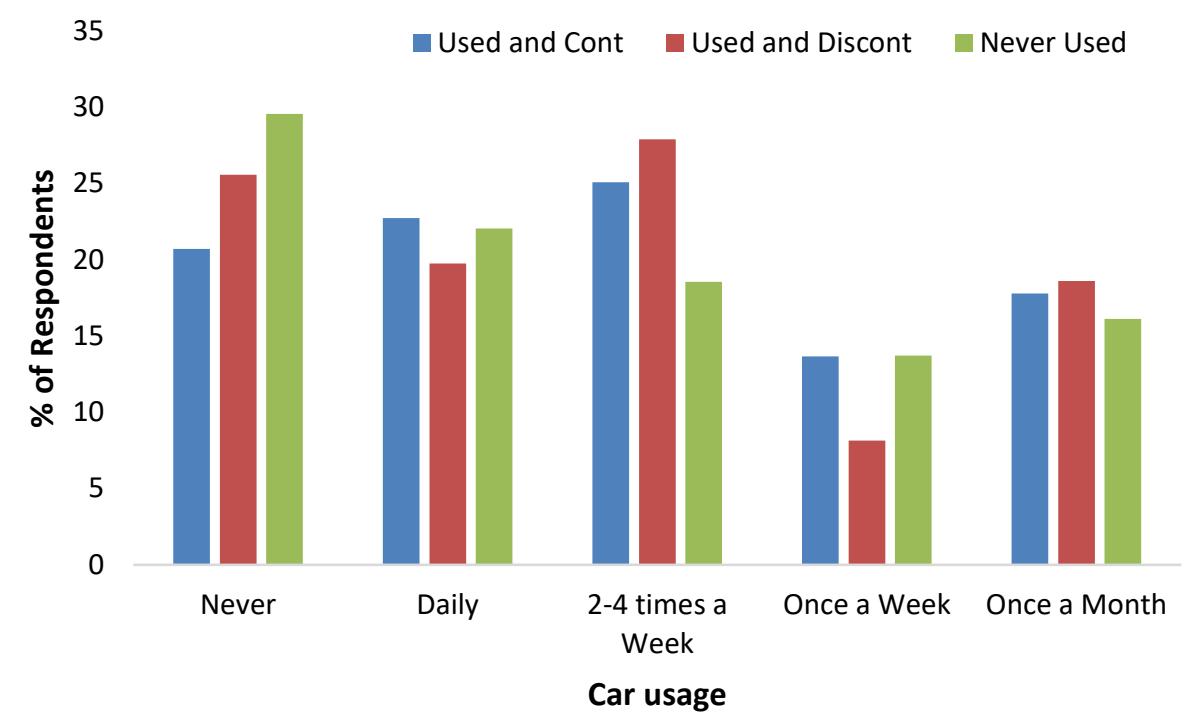

a)

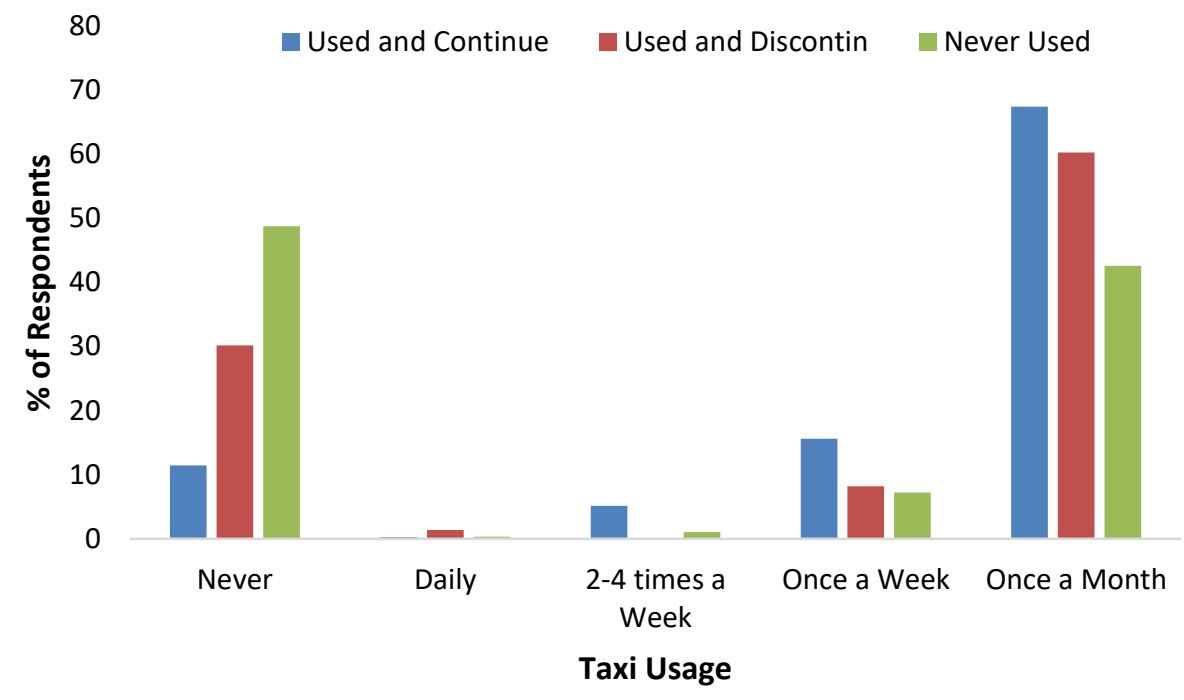

b)

Figure 5: Kutsuplus use in relation to a) Car use frequency and b) Taxi usage frequency 


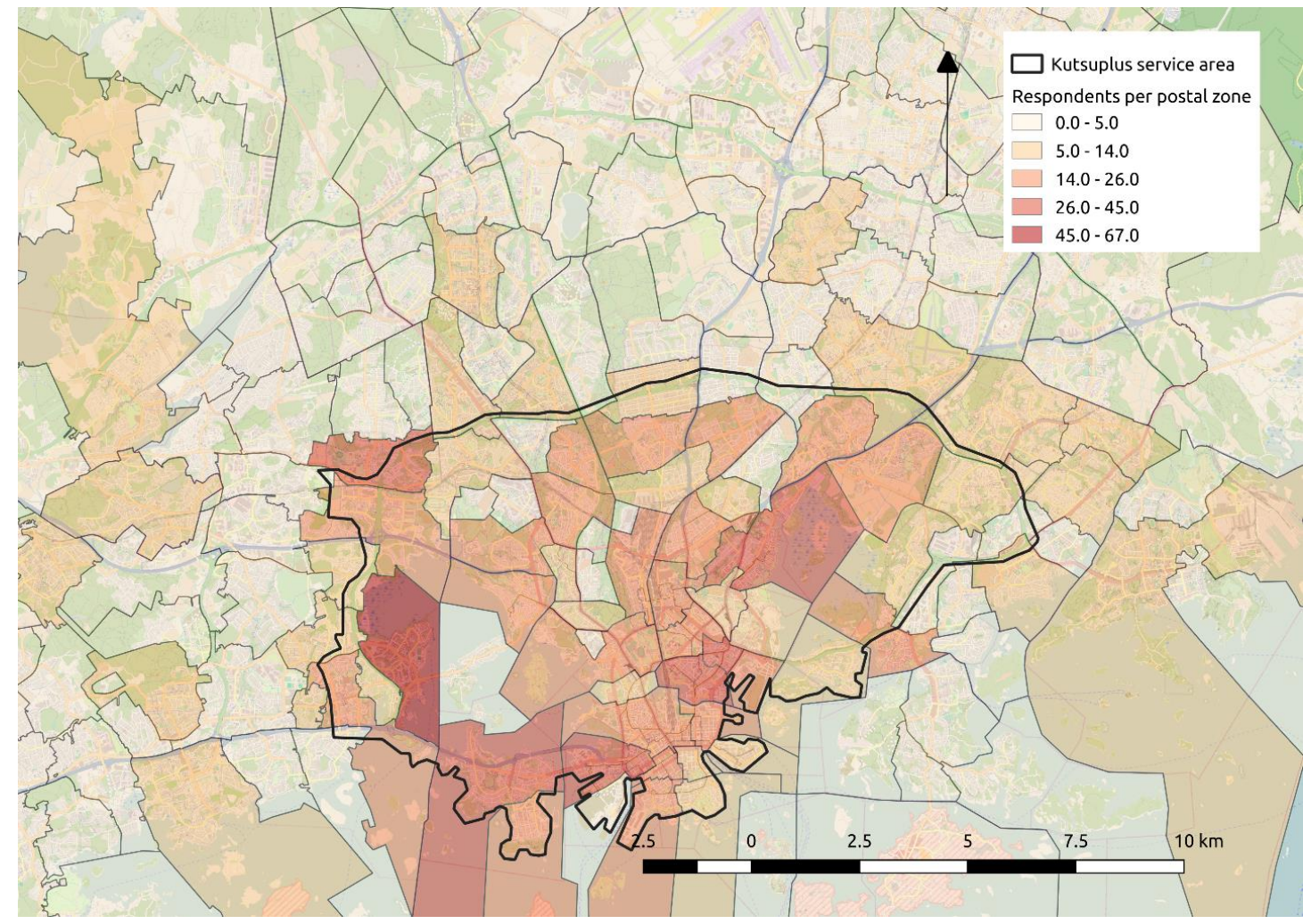

Figure 6 Spatial distribution of all survey respondents' place of residence (Background map () Open Street Map)

\subsection{General and Spatial Characteristics of Kutsuplus trips}

The diverse user base of Kutsuplus is reflected by the stated trip purposes (Figure 7). The questionnaire contained four predefined classes: going to work/school, business related trip, shopping trip and social/recreational trip. Based on the open answers two other classes of trips were identified: healthcare-related trips and children-related trips. Social/recreational trips were the largest class in all age groups. This trip purpose was also the most common throughout the day, except for the morning (6 to 10), where trips to work and schools were more common. When comparing the trip purposes to the results of the HSL travel survey, the most striking difference is the large proportion of business-related trips with Kutsuplus (Lindeqvist et al., 2013). Comparing to around $20 \%$ of business-related Kutsuplus trips, only $3 \%$ of all trips were business-related in the Helsinki region travel survey. In addition, the variation between age groups was relatively small. Hardly surprising, the only exception is the oldest age group (66 years or older), where the number of job and business-related trips are few while the recreational, healthcare-related and children-related trips have a higher proportion. The group of 
miscellaneous trips, with open ended answers that could not be assigned to any of the existing or new trip classes, included such trips as traveling with heavy luggage or pets, as well as trips to the ferry harbors in the inner city, without clarification of the trip purpose.

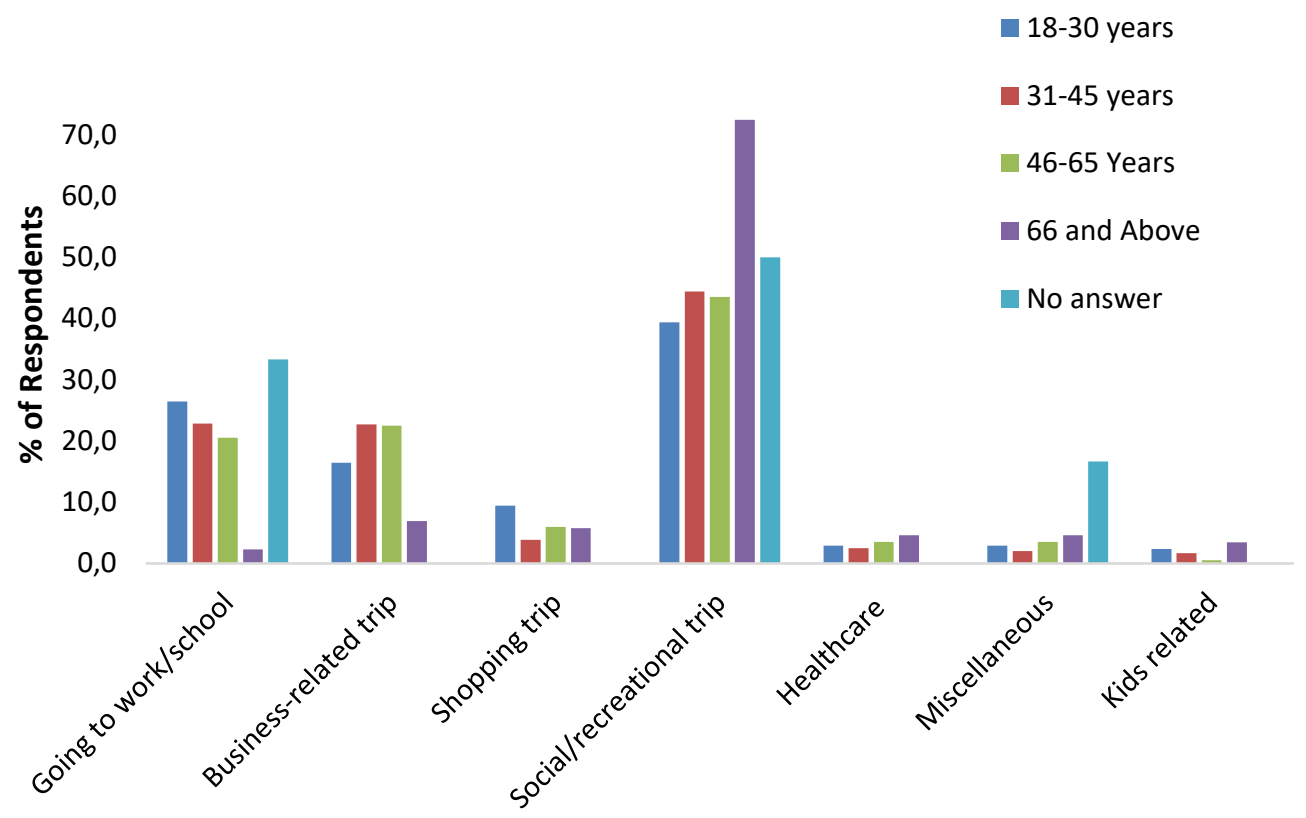

Trip Purpose

a)

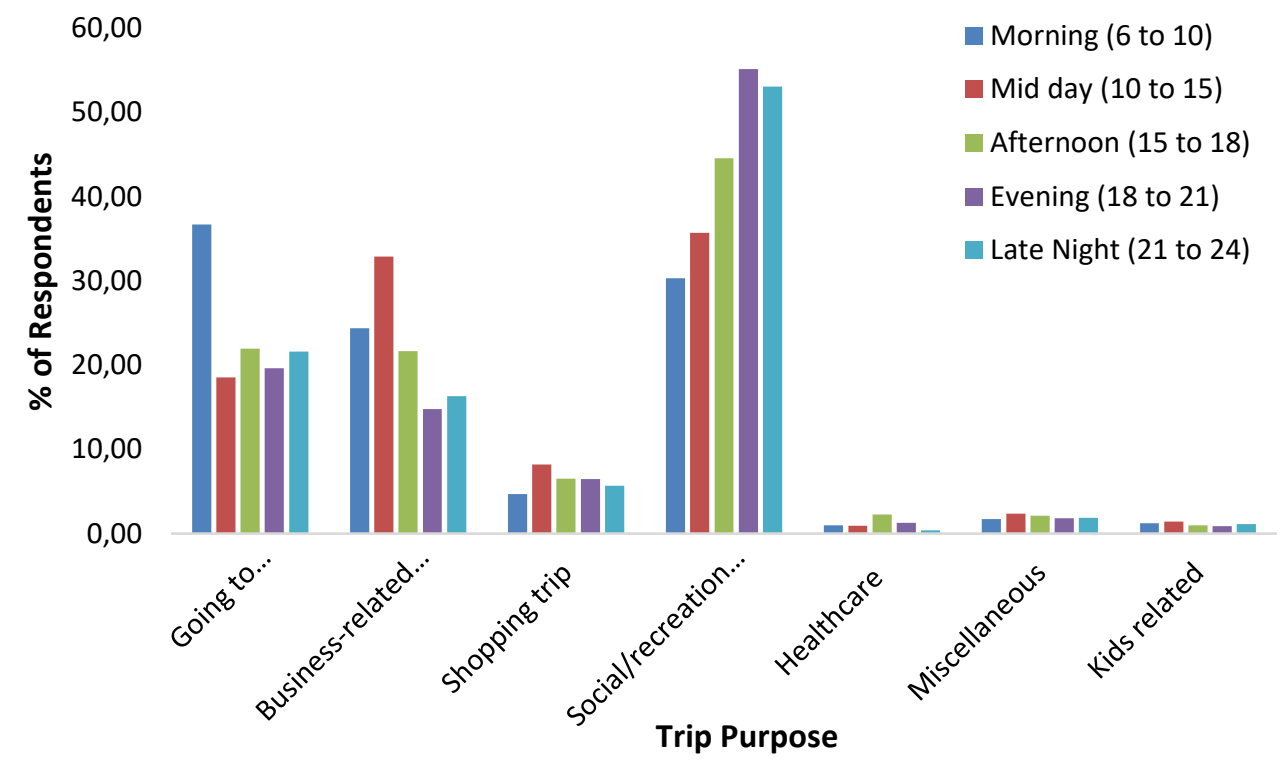

b)

Figure 7: Trip purpose in relation to a) Age groups and b) Time of day 
Figure 8 to Figure 10 show common trip origins and destinations, desire line distribution, and trip length distribution. In Figure 9, numbers in rectangles represent trips between zones (administrational district areas), while numbers in circles represent the number of internal trips. The patterns for the survey data and the Kutsuplus trip data are fairly similar. Based on the trip data collected in the survey, the highest concentration of origins and destinations were in the inner city, especially the central business district. These are the densest parts of the city regarding population and job density, as well as public transport network. Other hotspots are found in the Otaniemi campus and business area, Arabianranta (campus, business and residential), Munkkivuori (residential and business) and Lauttasaari (residential and business). In general, the peripheral areas had fewer origins and destinations, Otaniemi being the main exception (Figure 8). This would be partially expected due to the lower population and job density. A majority of the trips were made between and within the three central areas and the Otaniemi area. Trips orbital or transversal to the city center were fairly uncommon. The trip length distribution for Kutsuplus is compared to taxi trips (Figure 10). This figure shows a drop in the number of trips longer than nine kilometers, with largest group being trips between four and five kilometers. This distribution reflects the size of the service area and the fact that most trips are directed towards or within the central areas. The corresponding distribution for taxi trips originating or ending in the Helsinki capital area, shows a very even distribution, with significant proportion of trip extending out of the Kutsuplus service area. 


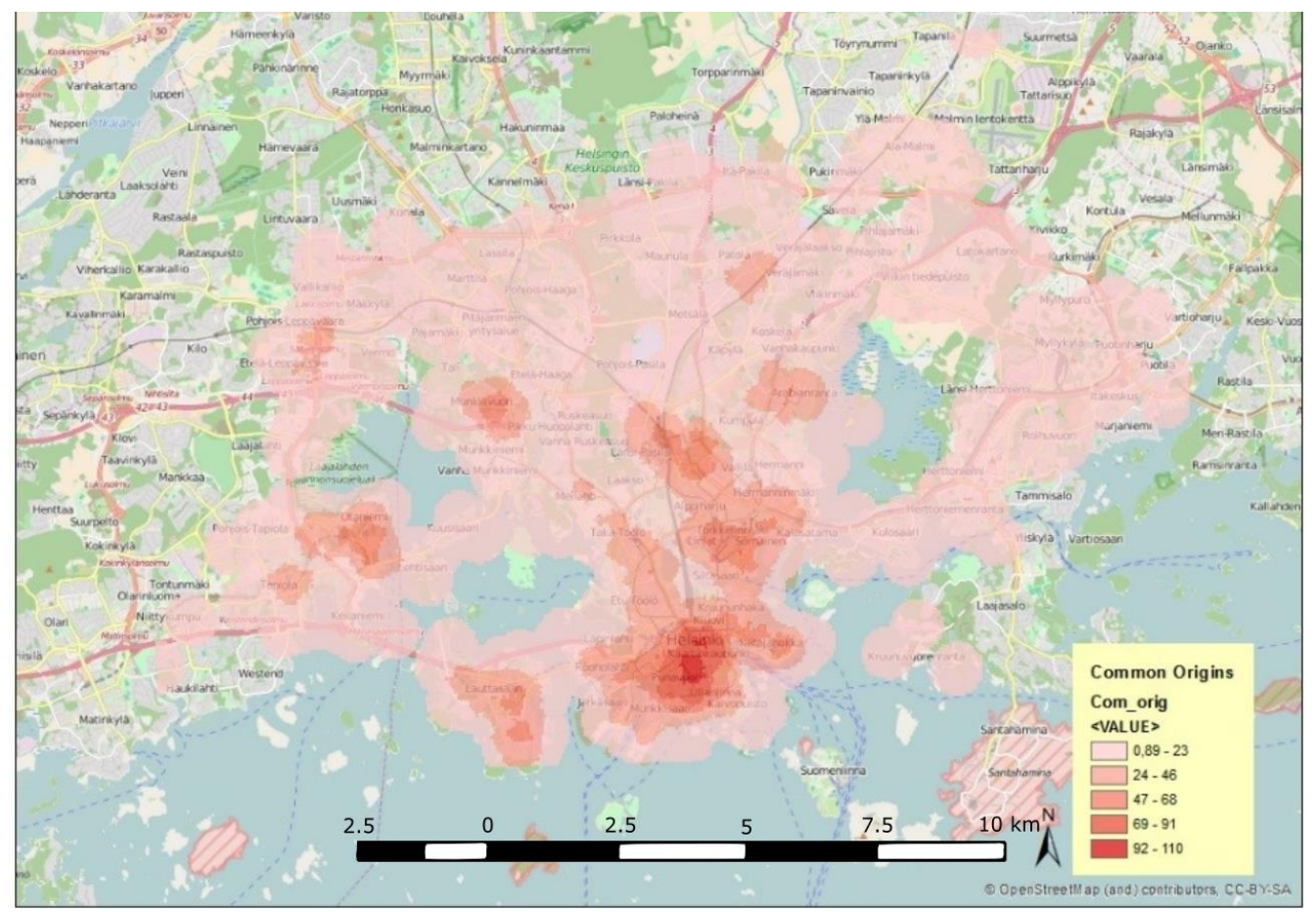

a)

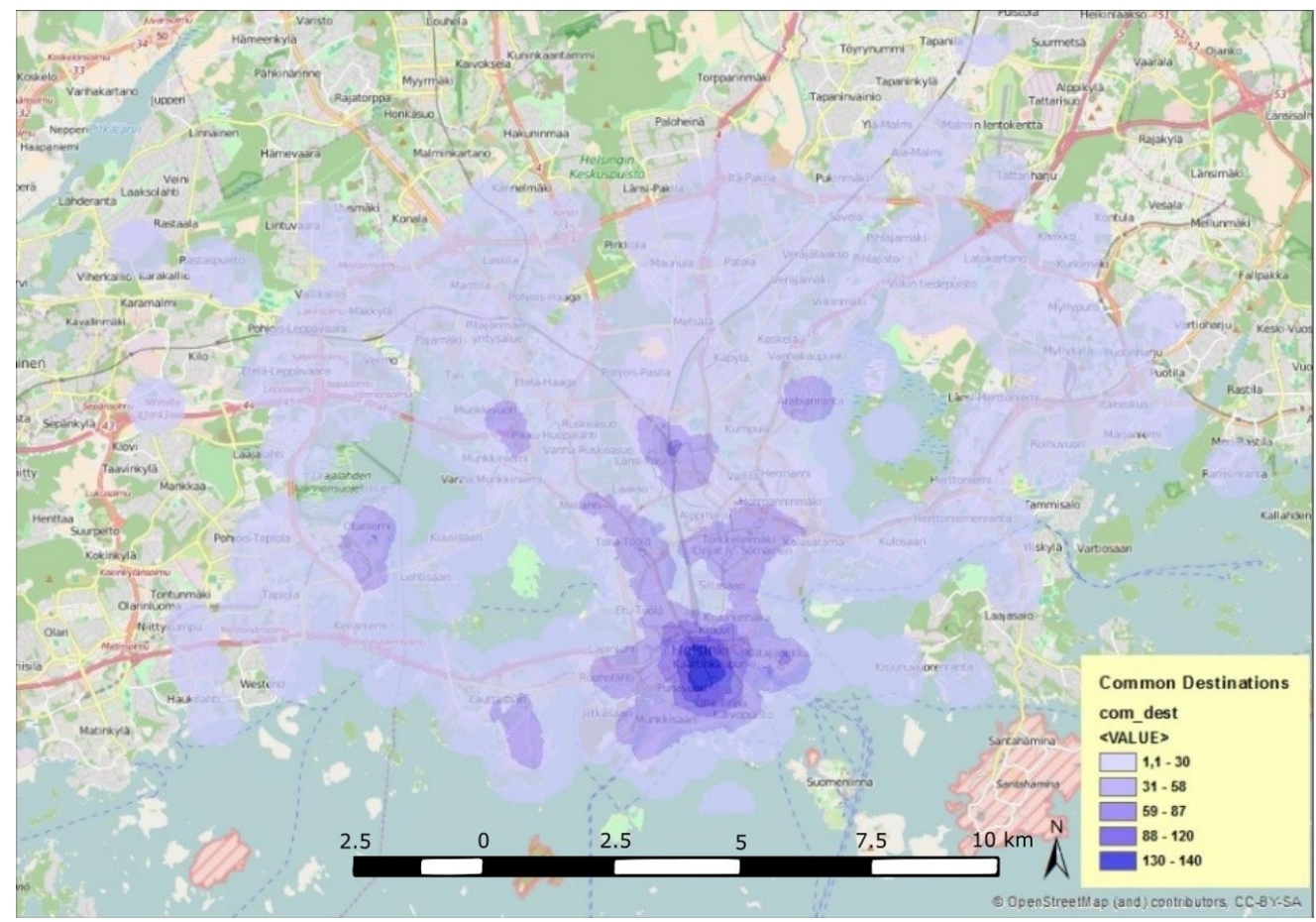

b)

Figure 8: Common trip a) origins and b) destinations (Background map @ Open Street Map) 


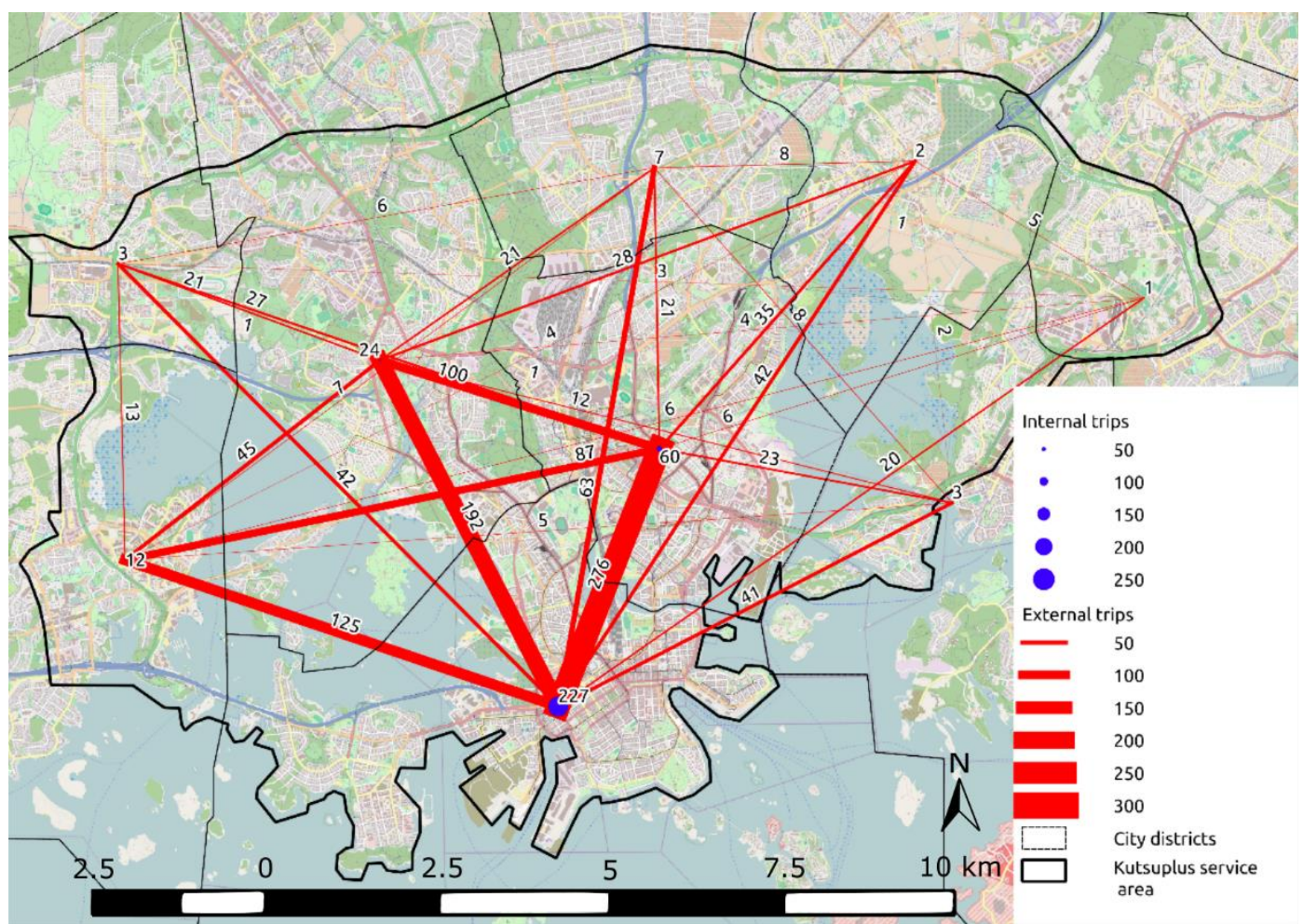

a)

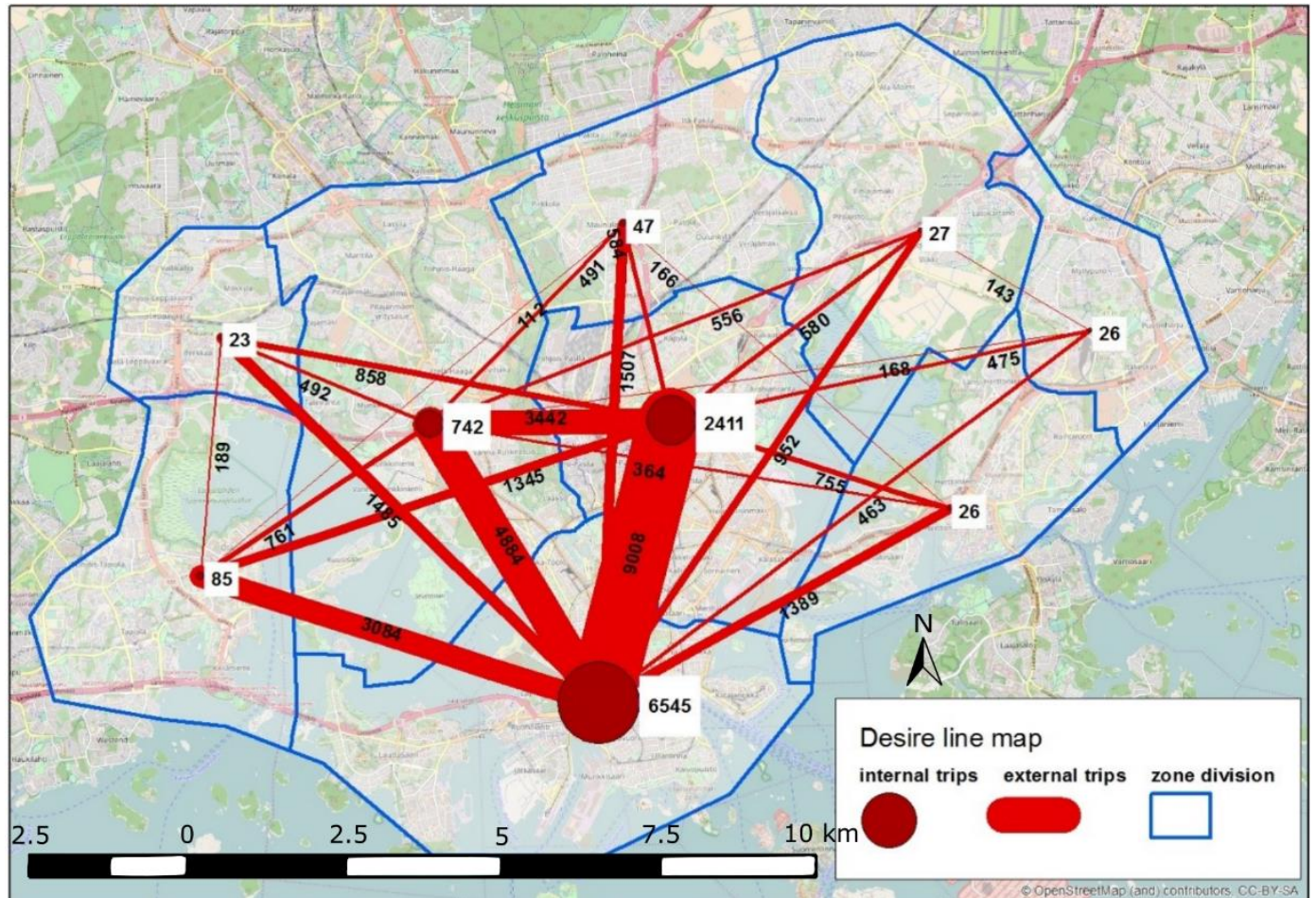

b)

Figure 9: Desire lines for trips using Kutsuplus, (a) based on survey and (b) Kutsuplus trip data for 2015 (Background map (c) Open Street Map) 


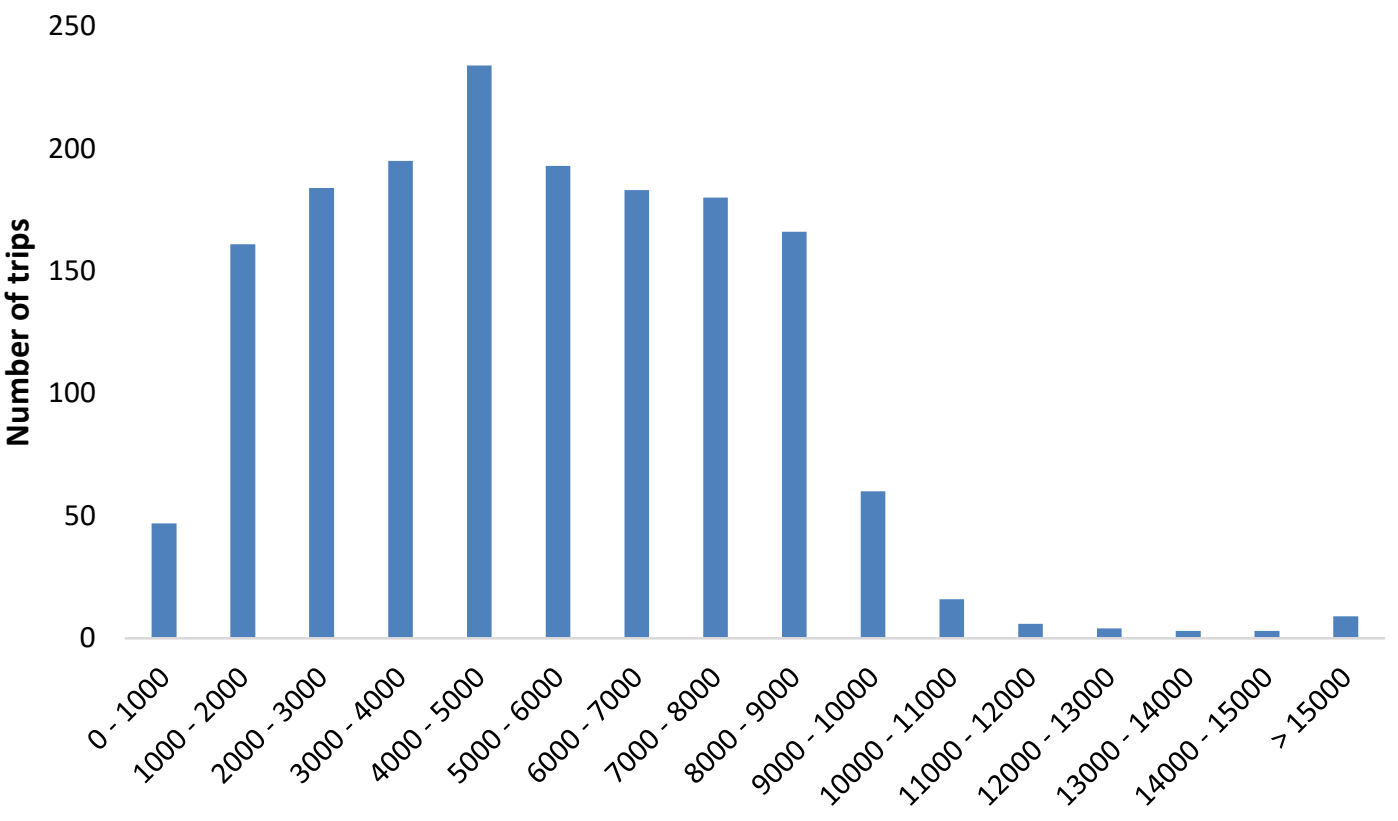

Trip length (m)

a)

25

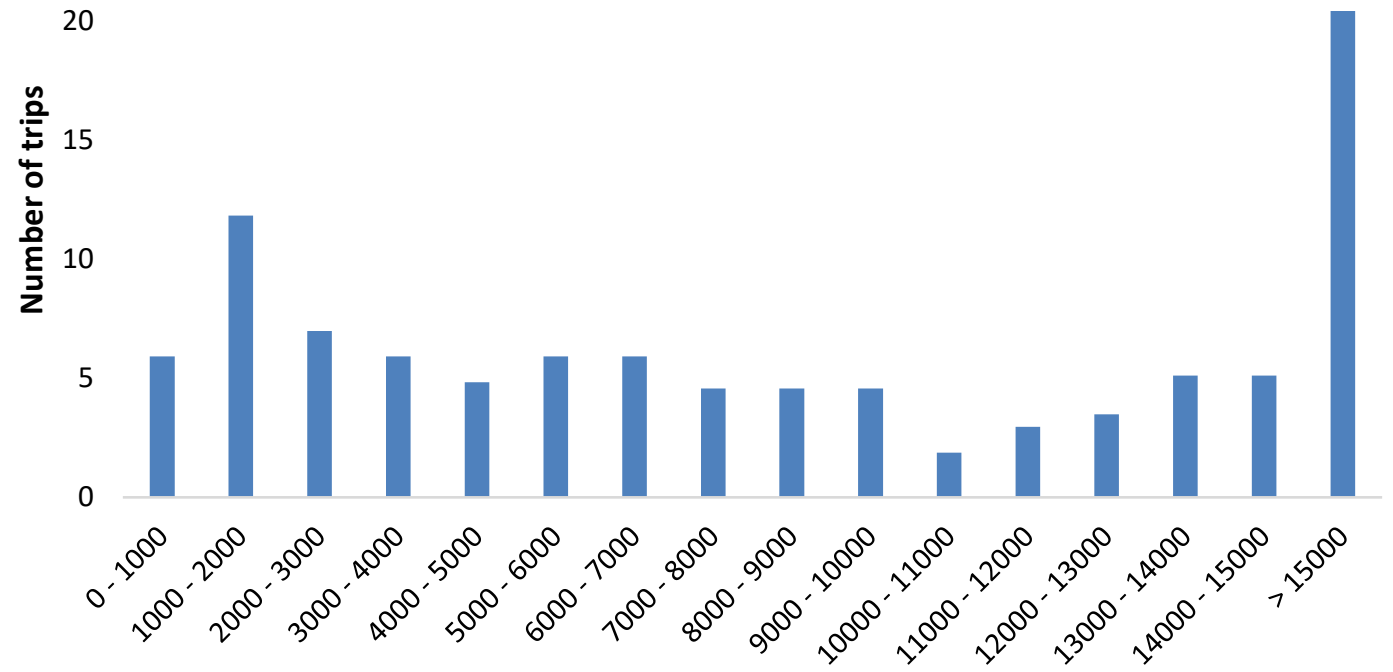

Trip length (m)

b)

Figure 10: Trip length distribution of Kutsuplus (a) and taxi (b) 


\subsection{Respondents' Opinions and Recommendations}

Figure 11 shows the respondents rating of the Kutsuplus service on a scale of one to five, with five being the maximum, and based on the decision to continue using Kutsuplus. One can conclude that the rating is more frequently higher for respondents who have not decided to stop using Kutsuplus, compared to those who have decided to stop using it. A weighted average score for those that have not decided to stop using the service is 4.64 , while it is 3.74 for those that have decided to stop using the service. The average user satisfaction rating in this study is very similar to results in previous user satisfaction studies when the system was operational (Rissanen, 2016).

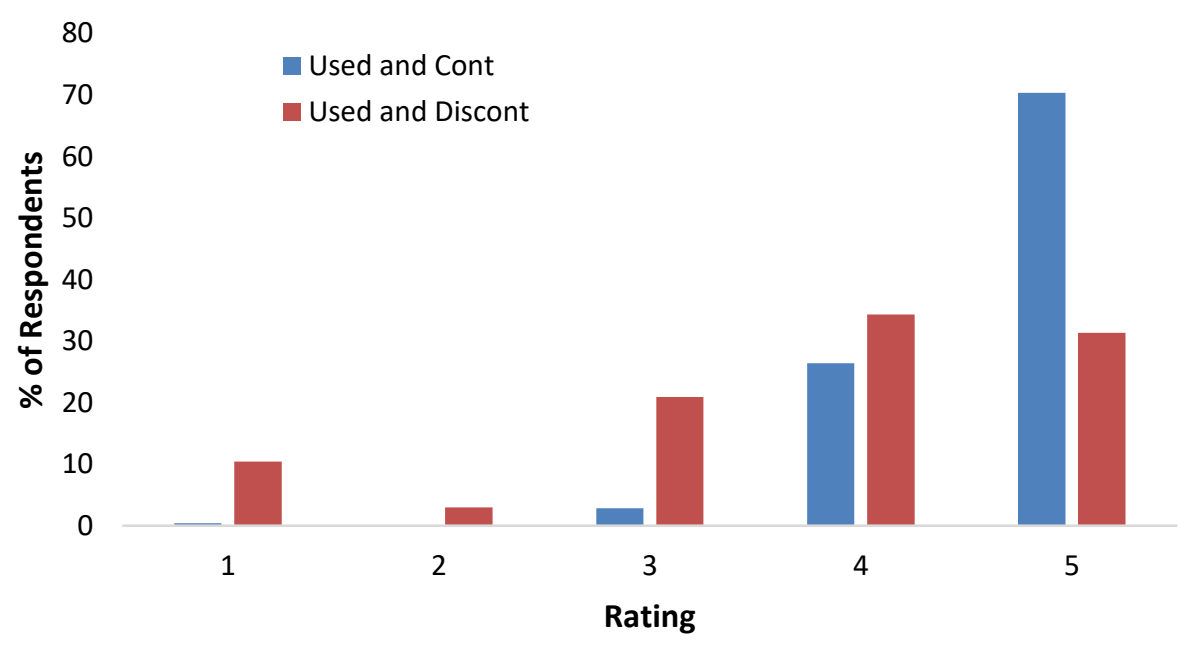

Figure 11: User rating in relation to service continuation

Figure 12 shows respondents' comments regarding the reasons for using Kutsuplus, for deciding to stop using Kutsuplus, and reasons for not using Kutsuplus, classified according to respondents' income category. One can conclude that most common reasons for using Kutsuplus are lack of good public transport connection, low cost compared to taxi, and fast travel choice compared to taxi. In addition, issues with using a car have been more often highlighted by respondents from higher income categories. Miscellaneous reasons for using Kutsuplus included curiosity to try new service, fast travel when accompanying a child, and traveling with heavy or large goods. Lower income categories mostly selected trip cost and use of other public transport modes as a reason for stopping the use of Kutsuplus. On the contrary, vehicle unavailability and long response times has affected more than $35 \%$ of respondents from higher income groups to 
stop using the service. Miscellaneous reasons for stopping the use of Kutsuplus included no advance-ordering feature, longer travel time from estimated, slower service compared to other public transport, removal of "fast" travel option, or failure to pick up after ordering. Respondents that have not used Kutsuplus service most frequently highlighted the lack of knowledge about the service. For the respondents in the lowest income categories, the service area was not often perceived as a problem, as opposed to the fare level, where all the complaints originate from this income group. One can observe a significant percentage of answers classified as miscellaneous. These responses included difficulty in ordering, limited service time, assumptions about comfort and reliability in comparison to taxi and car use.

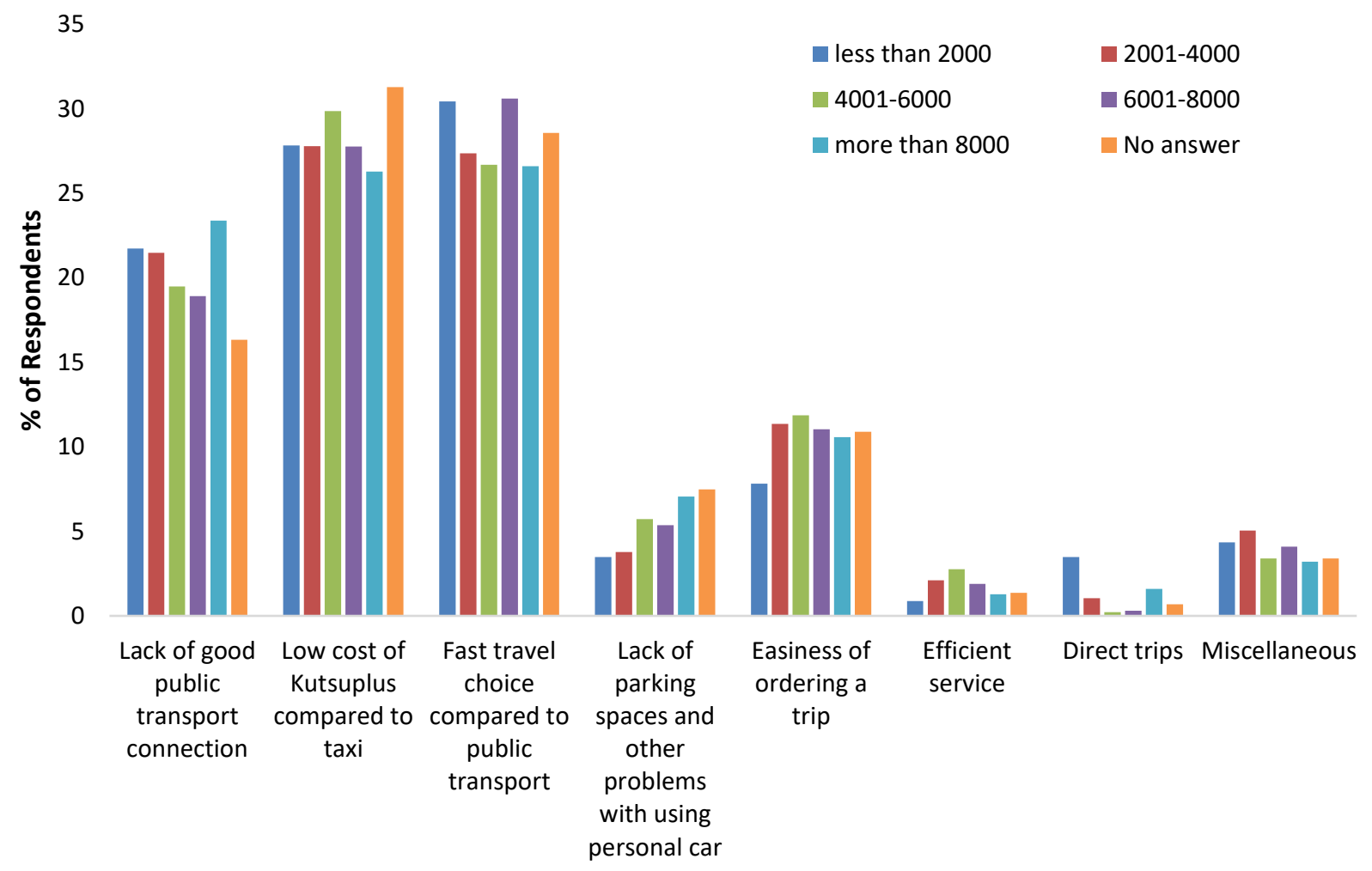

Reasons for Using Kutsuplus

a) 


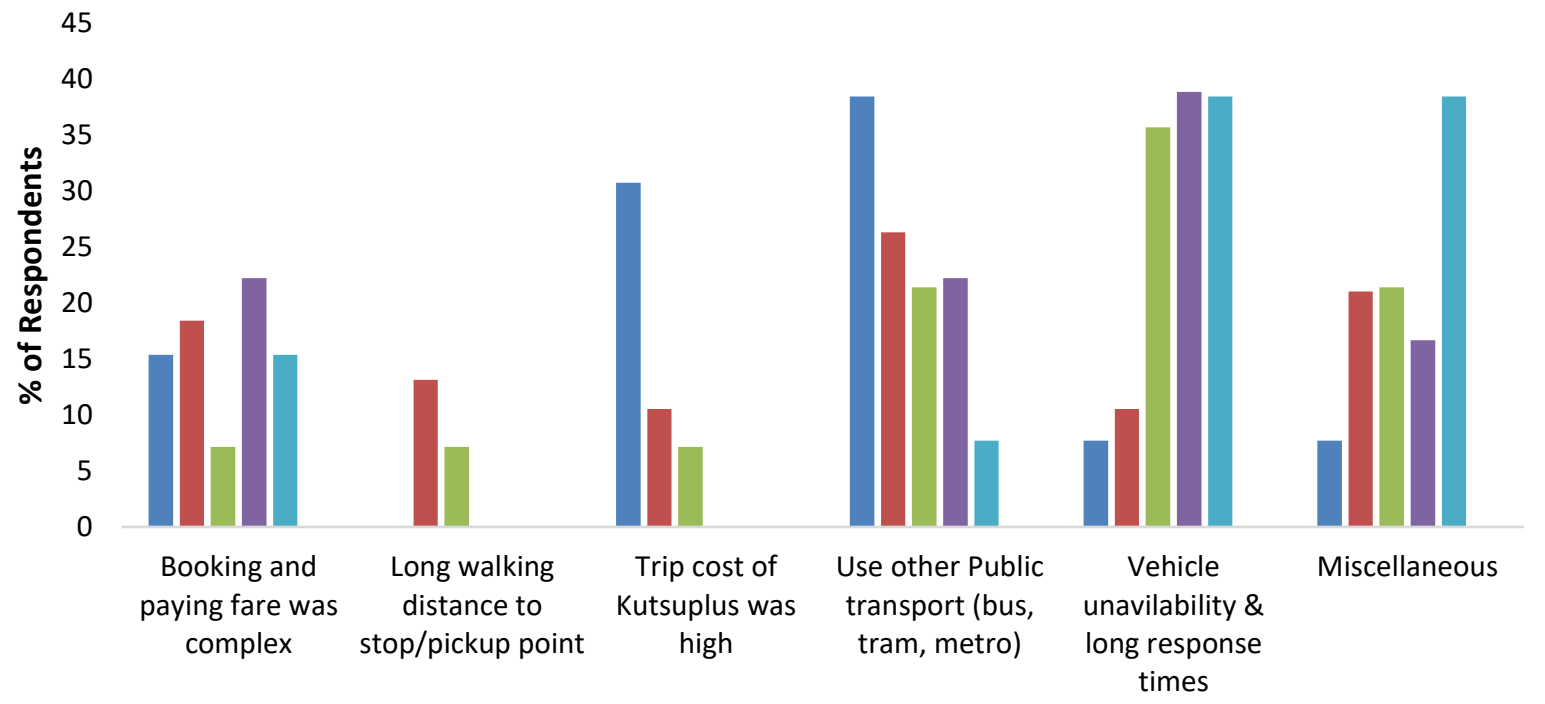

Reasons for Discontinuing the use of Kutsuplus

b)

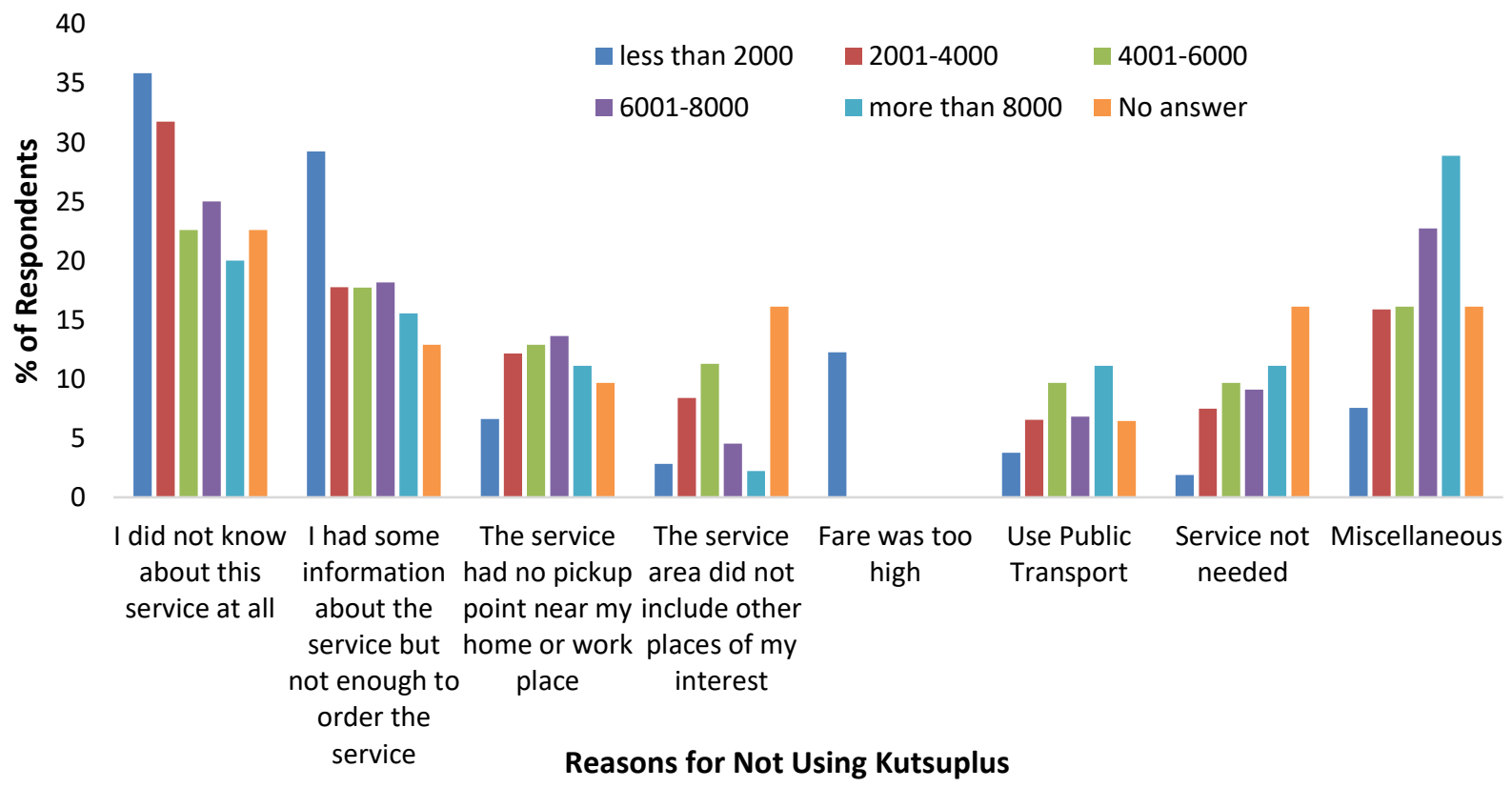

c)

Figure 12: Income in relation to a) Reasons for using Kutsuplus, b) Reasons for discontinuing use of Kutsuplus, and c) Reasons for not using Kutsuplus 
The questionnaire contained two open ended questions asking specifically about the positive Kutsuplus features and about suggestions for improvement in the case the service is relaunched. The first question was only directed to persons who had used the service while the second question was available for all respondents. As the questions were not structured, the answers varied in scope and quality. However, the answers were categorized based on the content.

The results in the open-ended question regarding the main positive features of Kutsuplus followed the pattern of the answers to the structured question regarding why Kutsuplus was used. Both in the structured and the open-ended questions the respondents greatly appreciated speed, affordability and to some extent the ease of ordering Kutsuplus. Kutsuplus was seen as complementing lacking public transport, both spatially, neighborhoods with bad connections but also temporarily at times of day when public transport is infrequent. The respondents also mentioned the comfort and appliances of the Kutsuplus vehicles (e.g., wireless Internet, electric socket), flexibility, reliability and the general effortlessness as positive features. In addition, the drivers were seen as friendly and helpful. Many appreciated the travel information, mainly in the form of an online real-time map where the Kutsuplus vehicles could be monitored. Less common answers mentioned the ease of traveling with heavy baggage, as sick or as disabled. Safety and children were often mentioned in the same answers, as some saw Kutsuplus as a safe way to send children alone to their hobbies or school. The fact that parents could order the trip, pay and even track the vehicle, enabling a checkup call when the destination was reached, were by some seen as key safety features. Kutsuplus was also seen by some as a safe way to get home in the evening. Some answers were very specific, such as appreciating the air-conditioned vehicles or removing the hassle of owning a car, while others answered from a general view, e.g. by stating that the service improved the quality of life or is innovative and modern.

Despite the many positive features of Kutsuplus and the high rating, both users and non-users found room for improvement of the service. One often commented feature was the limited size of the service area, with various suggestions for expansions. Commonly suggested expansions were to cover the whole urban area of Helsinki or add specific areas close to the current service area. The most common suggestion was adding the Helsinki airport, located at the extreme northern point of the urban area. In some answers the service area was seen as wrongly allocated to the 
areas with already functioning public transport and that the emphasis should be on complementing or even replacing lacking public transport services with Kutsuplus. One suggestion considered removing Kutsuplus altogether as an option for trips with traditional public transport that do not require transfers. The non-users often lived outside the service area which rendered the service useless for them. Many also wanted to improve the service coverage within the current service area by adding new stops. Especially healthcare facilities were suggested as locations for new stops as the persons needing medical treatment often are the ones benefiting most from short walking distances. There were many suggestions regarding an expansion in the temporal dimension. Both late evening, night and weekend service were frequently suggested.

Several respondents criticized the fare collection system. Prepayment was seen as inconvenient as it added an extra, often seen as unnecessary, step to using the service. Many respondents perceived the lack of payment alternatives as an obstacle for new users, as this required an effort to learn how to use the new system. Several alternatives were suggested, such as credit card payment, travel card payment, payment through phone bill or even cash. Another suggested payment option was based on a monthly subscription. Moreover, many respondents had opinions regarding pricing. Some demanded lower fares for everyone, but discounts were also suggested for special cases such as students, persons with a public transport season ticket, families and groups. Of these the group discount was already implemented, but perhaps poorly advertised. Some users also pointed out that pricing information was hard to access, especially for people that did not yet have an account but wanted to try the service. Despite many respondents hoping for a more affordable service there were also few respondents willing to increase the fares, especially for a potential weekend service or a for a re-implemented "fast" service without combined trips.

Many respondents have perceived ordering as functional. However, especially elderly persons would have hoped for an easier to use trip ordering interface or alternative ordering systems such as SMS ordering (that was implemented in the later stages) or ordering through phone service. In addition, there were few suggestions of integrating the ordering of Kutsuplus into the HSL online route planner used for traditional public transport. This would have made possible the direct 
comparison between traditional public transport and Kutsuplus. Many respondents have highlighted the small time window for ordering trips of typically 45 minutes before the desired departure as problematic. The possibility of advance ordering was frequently suggested, with the time range varying between a few hours to several days. Kutsuplus also lacked the possibility to order a trip with a requested latest arrival time. A less common request was to improve considering persons with daily need for trips with the same origin, destination and time of travel. Another suggested feature would have been the possibility to order a pick-up or drop-off chain for a group with a common destination or origin respectively. Many respondents would have preferred an application for smart phones instead of an Internet browser-based user interface. The Uber app was often mentioned as a good reference for an app design.

According to some respondents the reliability of the Kutsuplus system was deteriorating during rush hours as the passenger numbers grew. The decreased reliability took the form of long response times for the Kutsuplus vehicles, and longer or at least decreased travel time reliability. One reason mentioned by respondents for the decrease in travel time reliability was that it became more common that the trip would be combined with someone else's. The increased unreliability regarding response and travel times in combination with the ordering system that only allowed ordering 45 minutes before the desired departure time made Kutsuplus a "risky" option for trips where being on time was necessary. In a worst-case scenario, Kutsuplus would not be available and in addition it would be too late to use any alternative modes. A few respondents stated that these factors forced them to at least partially abandon using the system. The long response times also hindered some of the respondents to try the system. As a solution many suggested an increase in the number of Kutsuplus vehicles or alternatively integration with the taxi system.

Based on the low number of suggestions regarding the Kutsuplus algorithm, it can be assumed that the system worked well from this perspective. However, there were a few mentions of situations where the passenger was close to the destination, yet the Kutsuplus algorithm ordered the vehicle to turn back to pick up passengers far away in another direction. Another user suggested that there should be a cap on how many trip combinations would be allowed, to secure an acceptable travel time. To speed up passenger pick up, the algorithm was suggested to be 
changed so that the pick-up stop would be on that side of the road that required the minimum number of U-turns for the Kutsuplus vehicle.

The lack of marketing was by many seen as one of the main failures. Especially the respondents who had not tried the service would in many cases have liked to be informed about this option. Respondents wanted more information and detailed explanations of how to use the service. A free first ride was seen by some respondents as a good marketing trick. Many of the Kutsuplus users tried to recommend the service to friends and relatives. A common misconception encountered by them was that Kutsuplus was meant for elderly, as the service routes use similar microbuses. On the other hand, some respondents wanted vehicles with improved accessibility to indeed make it easier for elderly and disabled to use Kutsuplus.

\section{DISCUSSION AND CONCLUSIONS}

Kutsuplus service, as a unique pilot of urban FMTS in the world, enables a range of lessons. The service has involved a significant technological development, combining various data sources in real-time. In addition to the advances in FMTS technology, the pilot has enabled a range of empirical lessons related to marketing, fare policy, user interface, and spatial aspects. During its operation from October 2012 to the end of 2015, Kutsuplus had a growing user base, which also included frequent private car users. In addition, Kutsuplus had a growing number of annual trips, improving vehicular efficiency, high reliability, and decreasing subsidy per trip. In addition, user satisfaction had consistently high overall rating, of around 4.7 out of five. The high user satisfaction has also been observed from the respondents in this research.

In detail, Kutsuplus has been used for a range of trip purposes. However, socio-recreational trip purpose has been the most frequent one, with addition subcategories emerging, such as healthcare or child-related, or travel with luggage or pets. Moreover, Kutsuplus trips were geographically spread out over the whole area. However, most frequent trip origins and destinations centered on several, mostly business-related, locations. In addition, most Kutsuplus trips were below nine kilometers, which coincided with the radius of Kutsuplus service area. In summary, Kutsuplus had a range of positive features that have attracted and kept the users, including: 
- Good complementation with public transport in areas of low public transport accessibility;

- Low cost for the end user;

- Fast travel compared to public transport;

- Reduction in car-related issues, such as finding parking;

- Easiness to habituate into travel behavior once familiar with service;

- Benefit for special groups users (e.g., traveling with luggage, sending children);

- Riding comfort and amenities in the vehicle, including real-time information;

- Safety during traveling;

- Friendly staff;

- Innovativeness of the service.

\subsection{Methodological limitations}

The implemented methodology involved several tradeoffs, despite the relatively large survey sample. First, as the survey was conducted after the service termination, users' perception might have been skewed due to the closure, increasing the likelihood of higher emotional responses supporting the service resumption. Second, the dissemination channels used might have resulted in some bias of the sample composition, by making it difficult to respond for persons not using the social media channels. Furthermore, it is likely that the survey attracted users who were in favor of the service. As the number of respondents reached through various media channels is unknown it is thus impossible to define a distinct response rate, and consequently provide additional comments on the dissemination channel effect (AAPOR, 2016). However, the background questions regarding gender and age enables the comparison of the sample to the population in the Capital region consisting of Helsinki, Espoo, Vantaa and Kaunianen (Statistics Finland, 2018). The gender distribution for non-users and discontinued Kutsuplus users matches closely that of the region (females underrepresented by $0.3-0.5$ percentage units in the sample), while females are overrepresented among Kutsuplus users by 6 percentage units. The age distribution for non-users shows a 16 percentage units bias towards the youngest age group while the oldest age group is underrepresented by a similar magnitude (Table 3). The age groups in between, 31-45 years and 46-65 years, deviates by 0.5 and - 0.6 percentage units. The reason of the bias towards the younger age group is most likely caused by the dissemination channels used. 
However, the impact among Kutsuplus users is difficult to assess as the distributions among Kutsuplus users in the late stages of the service is unknown (Rissanen, 2016).

Third, the survey design involved a compromise between the length and a range of questions asked. For example, some additional questions, such as usage and perception of public transport could have been included. Instead, a proxy question of car and taxi service usage was used. Fourth, considering the range of changes during the pilot, additional questions related to the period of using the Kutsuplus service could have provided more insight into the contextual user experience.

Table 3 Age distribution in the region and among respondents by Kutsuplus use.

\begin{tabular}{|c|c|c|c|c|}
\hline $\begin{array}{c}\text { Regional adult } \\
\text { population }\end{array}$ & $21,85 \%$ & $27,89 \%$ & $29,98 \%$ & 66 and Above \\
\hline Never Used & $38,08 \%$ & $28,50 \%$ & $29,53 \%$ & $3,27 \%$ \\
\hline $\begin{array}{c}\text { Used and } \\
\text { Discontinued }\end{array}$ & $28,41 \%$ & $40,91 \%$ & $26,14 \%$ & $4,55 \%$ \\
\hline $\begin{array}{c}\text { Used and } \\
\text { Continued }\end{array}$ & $11,52 \%$ & $43,92 \%$ & $35,31 \%$ & $9,26 \%$ \\
\hline
\end{tabular}

\subsection{Implications for managerial practice}

Being operated as a publicly funded pilot, facing a gradual withdrawal of the fare subsidy, Kutsuplus had limitations with the operating budget. Even though the financing of the service, with an issue of available fleet size in particular, has become a significant obstacle for service continuation, several other groups of features that could have been improved are identified in the Kutsuplus' development trajectory. Contrary to the public discourse, the research results indicate that financial obstacles were just a "tip of the iceberg". In fact, there were several factors, where each of the factors is not significant, but in combination with other factors introduces barriers for successful technological transition. These inadequacies are also important focal points for future deployment of DRT services in urban environments.

- The first group of lessons relates to end user analysis. As a potential area of improvement, future urban DRT services should dedicate significant effort in clearly identifying the end user target groups. Moreover, service planning should avoid spanning 
over a range of users, from an alternative for car-dependent travelers to a service for all. In addition to end user analysis, the analysis should also focus on spatial and temporal patterns, with the potential to advance stop location, including virtual stops, as well as vehicle scheduling and routing mechanism.

- Similarly, marketing strategy should reflect the end user target group, and avoid solely focusing on advertising but also aim at education on how to use the service. To this end, the marketing campaign could deploy "soundbite" length visual media, aiming at frontloading the education effort at the start of the service. In addition, an analysis of marketing media is required, if one aims at particular groups of potential users (e.g., are car-dependent users reached in social media?).

- A third group of recommendations relates to service usability and integration in the lines of MaaS thinking. FMTS should use both web, SMS and smart phone app-based booking systems, as well as enabling preordering more than 45 minutes in advance. The capabilities of online environments also allow for integration of the booking system with existing public transport routing planners. In addition, improving usability relates to integration into the existing public transport fare system, as well as enabling post-paid options, such as credit card or phone bill charge.

\subsection{Contribution to scholarly knowledge}

This research highlights the complexity of breaking the car dependency in the urban transport systems, pointing out a range of interdependencies that play a decisive role in success of FMTS. However, there are several other opportunities for further research. The first aspect is to focus on in-depth analysis of users and non-users travel habits, and the role that Kutsuplus service had in shaping them. Second, there is a need for detailed analysis of actual trips served by Kutsuplus, the impact of the pricing schemes, as well as comparison with other modes, such as passenger car and public transport. Finally, there is a need for developing policy and planning recommendations for integrated planning and operations of FMTS and static public transport network service in conjunction with the MaaS approach. 


\section{ACKNOWLEDGMENT}

This research has been partially funded by the Academy of Finland project "DecoNet" (No. 295499). In addition, the authors would like to thank Helsinki Region Transport Authority for

providing valuable information and support in disseminating the questionnaire. In particular, the authors would acknowledge the help of Kari Rissanen, Heli Rautio, and Eeva Jakobsson. Finally, the authors would like to thank Teemu Sihvola for providing Kutsuplus trip data.

\section{REFERENCES}

AAPOR. (2016). Standard Definitions: Final Dispositions of Case Codes and Outcome Rates for Surveys. 9th edition.

Agatz, N., Erera, A., Savelsbergh, M., \& Wang, X. (2012). Optimization for dynamic ridesharing: A review. European Journal of Operational Research, 223(2), 295-303. https://doi.org/10.1016/J.EJOR.2012.05.028

Ambrosino, G., Boero, M., Eloranta, P., Engels, D., Finn, B., \& Sassoli, P. (2000). Flexible Mobility Solutions in Europe Through Cooperation Between Operators, IT Suppliers and Authorities. In 7th ITS World Congress (p. 9).

Ambrosino, G., Nelson, J. D., Boero, M., \& Pettinelli, I. (2016). Enabling intermodal urban transport through complementary services: From Flexible Mobility Services to the Shared Use Mobility Agency: Workshop 4. Developing inter-modal transport systems. Research in Transportation Economics, 59, 179-184. https://doi.org/10.1016/j.retrec.2016.07.015

Anderson, D. N. (2014). "Not just a taxi"? For-profit ridesharing, driver strategies, and VMT. Transportation, 41(5), 1099-1117. https://doi.org/10.1007/s11116-014-9531-8

Banister, D. (2008). The sustainable mobility paradigm. Transport Policy, 15(2), 73-80. https://doi.org/10.1016/j.tranpol.2007.10.005

Black, W. R., \& Van Geenhuizen, M. (2006). ICT innovation and sustainability of the transport sector. European Journal of Transport and Infrastructure Research EJTIR, 6 (1).

Brake, J., Mulley, C., Nelson, J. D., \& Wright, S. (2007). Key lessons learned from recent experience with Flexible Transport Services. Transport Policy, 14(6), 458-466. https://doi.org/10.1016/j.tranpol.2007.09.001

Brake, J., Nelson, J. D., \& Wright, S. (2004). Demand responsive transport: towards the emergence of a new market segment. Journal of Transport Geography, 12(4), 323-337. 
https://doi.org/10.1016/j.jtrangeo.2004.08.011

Cannon, S., \& Summers, L. H. (2014). How Uber and the sharing economy can win over regulators. Harvard Business Review, 13(10), 24-28.

Diana, M. (2006). The importance of information flows temporal attributes for the efficient scheduling of dynamic demand responsive transport services. Journal of Advanced Transportation, 40(1), 23-46. https://doi.org/10.1002/atr.5670400103

Häme, L. (2011). An adaptive insertion algorithm for the single-vehicle dial-a-ride problem with narrow time windows. European Journal of Operational Research, 209(1), 11-22. https://doi.org/10.1016/J.EJOR.2010.08.021

Hensher, D. A. (2017). Future bus transport contracts under a mobility as a service (MaaS) regime in the digital age: Are they likely to change? Transportation Research Part A: Policy and Practice, 98, 86-96. https://doi.org/10.1016/J.TRA.2017.02.006

HSL. (2015). Helsingin seudun liikenne - Vuosikertomus 2015. Helsinki. Retrieved from https://www.hsl.fi/sites/default/files/hs1_vuosikertomus_fi_2015_aukeamat_0.pdf

HSL. (2016). Calculation of the estimated environmental benefits of Kutsuplus. Helsinki Regional Transport Authority. Retrieved from https://www.hsl.fi/uutiset/2015/hsl-selvittikutsuplus-liikenteen-hyotyja-7425

Jokinen, J.-P. (2016). On the Welfare Optimal Policies in Demand Responsive Transportation and Shared Taxi Services. Journal of Transport Economics and Policy, 50(1), 39-55.

Jokinen, J.-P., Sihvola, T., Hyytia, E., \& Sulonen, R. (2011). Why urban mass demand responsive transport? In 2011 IEEE Forum on Integrated and Sustainable Transportation Systems (pp. 317-322). IEEE. https://doi.org/10.1109/FISTS.2011.5973631

Jokinen, J.-P., Sihvola, T., \& Mladenovic, M. N. (2017). Policy lessons from the flexible transport service pilot Kutsuplus in the Helsinki Capital Region. Transport Policy. https://doi.org/10.1016/J.TRANPOL.2017.12.004

Kalliomaki, A., Eloranta, P., \& Sassoli, P. (2004). Organisational, institutional and juridical issues. In G. Abrosino (Ed.), Demand responsive transport services: Towards the flexible mobility agency. ENEA: Italian National Agency for New Technologies, Energy and the Environment.

Koffmann, D. (2016). Transportation Network Companies and Paratransit: Issues and Opportunities. In C. Mulley \& J. D. Nelson (Eds.), Paratransit: Shaping the Flexible 
Transport Future (pp. 377-390). Emerald.

Lindeqvist, M., Kantele, S., Räty, P., Elolähde, T., \& Vihervuori, M. (2013). HLJ 2015 Travel behavior in the Helsinki region in 2012. Helsinki. Retrieved from https://www.hsl.fi/sites/default/files/uploads/liikkumistottumukset_helsingin_seudulla_2012 _hlj2015_raportti_0.pdf

Mageean, J., \& Nelson, J. D. (2003). The evaluation of demand responsive transport services in Europe. Journal of Transport Geography, 11(4), 255-270. https://doi.org/10.1016/S09666923(03)00026-7

Mulley, C., \& Nelson, J. D. (2016). Shaping the New Future of Paratransit. Transportation Research Record: Journal of the Transportation Research Board, 2542, 17-24. https://doi.org/10.3141/2542-03

Nelson, J. D., Wright, S., Masson, B., Ambrosino, G., \& Naniopoulos, A. (2010). Recent developments in Flexible Transport Services. Research in Transportation Economics, 29(1), 243-248. https://doi.org/10.1016/J.RETREC.2010.07.030

Pangbourne, K., Stead, D., Mladenović, M., \& Milakis, D. (2018). The Case of Mobility as a Service: A Critical Reflection on Challenges for Urban Transport and Mobility Governance. In Governance of the Smart Mobility Transition (pp. 33-48). Emerald Publishing Limited. https://doi.org/10.1108/978-1-78754-317-120181003

Rissanen, K. (2014). Kutsuplus.fi - a Novel, Automated Real-time Demand Responsive Public Transport Service. In 10th ITS European Congress, Helsinki, Finland 16-19 June 2014 (pp. 16-19).

Rissanen, K. (2016). Kutsuplus - Final Report. Retrieved from https://www.hsl.fi/sites/default/files/uploads/8_2016_kutsuplus_finalreport_english.pdf

Salonen, M., Broberg, A., Kyttä, M., \& Toivonen, T. (2014). Do suburban residents prefer the fastest or low-carbon travel modes? Combining public participation GIS and multimodal travel time analysis for daily mobility research. Applied Geography, 53, 438-448. https://doi.org/10.1016/j.apgeog.2014.06.028

Sihvola, T., Jokinen, J.-P., \& Sulonen, R. (2012). User Needs for Urban Car Travel. Transportation Research Record: Journal of the Transportation Research Board, 2277, 7581. https://doi.org/10.3141/2277-09

Statistics Finland. (2018). Paavo - Open data by postal code area. Retrieved June 25, 2018, from 
https://www.tilastokeskus.fi/tup/paavo/index.html

Velaga, N., Nelson, J., Wright, S., \& Farrington, J. (2012). The Potential Role of Flexible Transport Services in Enhancing Rural Public Transport Provision. Journal of Public Transportation, 15(1), 111-131. https://doi.org/10.5038/2375-0901.15.1.7 